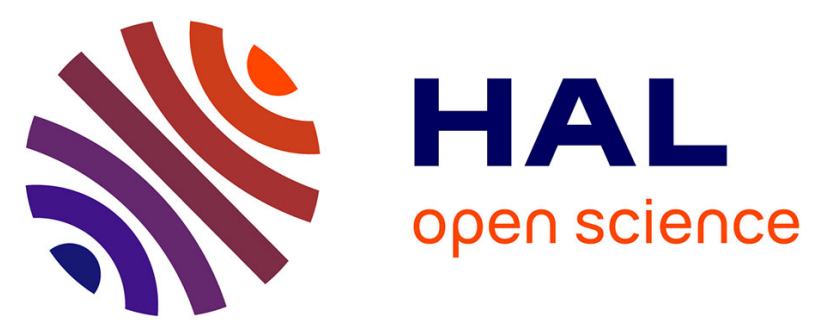

\title{
Nanomaterial grouping: Existing approaches and future recommendations
}

\author{
Anna Giusti, Rambabu Atluri, Rositsa Tsekovska, Agnieszka Gajewicz, \\ Margarita D. Apostolova, Chiara L. Battistelli, Eric A.J. Bleeker, Cecilia \\ Bossa, Jacques Bouillard, Maria Dusinska, et al.
}

\section{To cite this version:}

Anna Giusti, Rambabu Atluri, Rositsa Tsekovska, Agnieszka Gajewicz, Margarita D. Apostolova, et al. Nanomaterial grouping: Existing approaches and future recommendations. NanoImpact, 2019, 16, pp.art. 100182. 10.1016/j.impact.2019.100182 . ineris-03319071

\section{HAL Id: ineris-03319071 https://hal-ineris.archives-ouvertes.fr/ineris-03319071}

Submitted on 11 Aug 2021

HAL is a multi-disciplinary open access archive for the deposit and dissemination of scientific research documents, whether they are published or not. The documents may come from teaching and research institutions in France or abroad, or from public or private research centers.
L'archive ouverte pluridisciplinaire HAL, est destinée au dépôt et à la diffusion de documents scientifiques de niveau recherche, publiés ou non, émanant des établissements d'enseignement et de recherche français ou étrangers, des laboratoires publics ou privés. 


\section{Nanomaterial Grouping: Existing Approaches and Future Recommendations}

Anna Giusti ${ }^{1 *}$, Rambabu Atluri ${ }^{2,3^{*}}$, Rositsa Tsekovska ${ }^{4 *}$, Agnieszka Gajewicz ${ }^{5 *}$, Margarita D. Apostolova ${ }^{4}$, Chiara L. Battistelli ${ }^{6}$, Eric A.J. Bleeker ${ }^{7}$, Cecilia Bossa ${ }^{6}$, Jacques Bouillard ${ }^{8}$, Maria Dusinska ${ }^{9}$, Paloma Gómez-Fernández ${ }^{10}$, Roland Grafström ${ }^{11,12}$, Maciej Gromelski ${ }^{5}$, Yordan Handzhiyski ${ }^{4}$, Nicklas Raun Jacobsen ${ }^{2}$, Paula Jantunen ${ }^{13}$, Keld Alstrup Jensen ${ }^{2}$, Agnieszka Mech ${ }^{13}$, José Maria Navas ${ }^{14}$, Penny Nymark ${ }^{11,12}$, Agnes G. Oomen ${ }^{7}$, Tomasz Puzyn ${ }^{5}$, Kirsten Rasmussen ${ }^{13}$, Christian Riebeling ${ }^{1}$, Isabel Rodriguez-Llopis ${ }^{10}$, Stefania Sabella ${ }^{15}$, Juan Riego Sintes ${ }^{13}$, Blanca SuarezMerino $^{16,17}$, Speranta Tanasescu ${ }^{18}$, Håkan Wallin ${ }^{2,19}$, Andrea Haase $^{1 \#}$

1 German Federal Institute for Risk Assessment (BfR), Department of Chemical and Product Safety, Berlin, Germany

2 National Research Centre for the Working Environment (NRCWE), Copenhagen, Denmark

3 Infingent Innovations AB, Malmö, Sweden

4 Roumen Tsanev Institute of Molecular Biology - Bulgarian Academy of Sciences (IMB-BAS), Sofia, Bulgaria

5 Laboratory of Environmental Chemometrics, Faculty of Chemistry, University of Gdańsk (UG), Gdańsk, Poland

6 Istituto Superiore di Sanità (ISS), Environment and Health Department, Rome, Italy

7 National Institute for Public Health and the Environment (RIVM), Bilthoven, The Netherlands

8 National Institute for Industrial Environment and Risks (INERIS), Verneuil-en-Halatte, France

9 Norwegian Institute for Air Research, Department of Chemistry (NILU), Kjeller, Norway

10 Gaiker Technology Centre, Parque Tecnologico de Bizkaia, Bizkaia, Spain

11 Institute of Environmental Medicine, Karolinska Institutet (KI), Stockholm, Sweden

12 Division of Toxicology, Misvik Biology, Turku, Finland

13 European Commission - Joint Research Centre (JRC), Ispra (VA), Italy

14 National Institute for Agricultural and Food Research and Technology (INIA), Department of Environment, Madrid, Spain

15 Istituto Italiano di Tecnologia (IIT), Drug Discovery and Development Department, Genova, Italy

16 TEMAS AG, Zürich, Switzerland

17 Swiss Center for Applied Human Toxicology (SCAHT), Basel, Switzerland

18 Institute of Physical Chemistry (IPC) "Ilie Murgulescu" of the Romanian Academy, Bucharest, Romania

19 National Institute of Occupational Health, Oslo, Norway

*authors contributed equally

\# corresponding author: Andrea Haase, German Federal Institute for Risk Assessment (BfR), Department of Chemical and Product Safety, Berlin, Germany, andrea.haase@bfr.bund.de 


\begin{abstract}
The physico-chemical properties of manufactured nanomaterials (NMs) can be fine-tuned to obtain different functionalities addressing the needs of specific industrial applications. The physico-chemical properties of NMs also drive their biological interactions. Accordingly, each NM requires an adequate physico-chemical characterization and potentially an extensive and time-consuming (eco)toxicological assessment, depending on regulatory requirements. Grouping and read-across approaches, which have already been established for chemicals in general, are based on similarity between substances and can be used to fill data gaps without performing additional testing. Available data on "source" chemicals are thus used to predict the fate, toxicokinetics and/or (eco)toxicity of structurally similar "target" chemical(s). For NMs similar approaches are only beginning to emerge and several challenges remain, including the identification of the most relevant physico-chemical properties for supporting the claim of similarity. In general, NMs require additional parameters for a proper physico-chemical description. Furthermore, some parameters change during a NM's life cycle, suggesting that also the toxicological profile may change.

This paper compares existing concepts for NM grouping, considering their underlying basic principles and criteria as well as their applicability for regulatory and other purposes. Perspectives and recommendations based on experiences obtained during the EU Horizon 2020 project NanoReg2 are presented. These include, for instance, the importance of harmonized data storage systems, the application of harmonized scoring systems for comparing biological responses, and the use of highthroughput and other screening approaches. We also include references to other ongoing EU projects addressing some of these challenges.
\end{abstract}

Keywords: grouping, read-across, nanomaterials, toxicity prediction, risk assessment, category approach, analogue approach 


\section{Introduction}

Due to their enhanced or unique functionalities, nanomaterials (NMs) find applications in a wide range of industrial sectors such as building and construction, electronics, energy storage, packaging, paints, adhesives, textiles, consumer products, as well as health care (Forster et al. 2011). The physico-chemical properties of manufactured NMs can be modified and fine-tuned, e.g. via alteration of the surface chemistry, resulting in an extensive variety of NMs. In this paper, the term "nanomaterial" (NM) follows the recommended definition of the European Commission (EC) in which a "'nanomaterial' means a natural, incidental or manufactured material containing particles, in an unbound state or as an aggregate or as an agglomerate and where, for $50 \%$ or more of the particles in the number size distribution, one or more external dimensions is in the size range $1 \mathrm{~nm}-100 \mathrm{~nm}$ " and in which fullerene, graphene and carbon nanotubes that may have minimum diameters below $1 \mathrm{~nm}$, are included by default (EU 2011/696). The physico-chemical characteristics and properties of NMs determine their functionality and affects their environmental distribution, biological uptake, bio-distribution, potential dissolution and transformation and (eco)toxicity. Thus, each NM requires extensive characterization of its physico-chemical characteristics and properties, and a proper (eco)toxicity assessment, rendering hazard and risk assessment time-consuming and costly. Accordingly, in the last decade the development of grouping approaches for NMs has attracted huge interest among researchers, industry and regulators. Several NM grouping concepts have already been published, sharing some commonalities but also showing differences, e.g. in the grouping criteria considered or in the purpose for which the concepts have been developed.

\section{Grouping of chemicals}

Grouping and read-across can be applied for different purposes (ECHA 2017a, Bossa et al. 2018). They are most commonly used for regulatory purposes, where they may justify waiving specific tests or allow filling in of data gaps by read-across. Indeed, different European chemical legislation allow for grouping and read-across (Mech et al. 2018) as an alternative approach to provide data. For example under the overarching, horizontal legislation on the Registration, Evaluation, Authorisation and Restriction of Chemicals, REACH (EC 1907/2006), which broadly covers almost all chemicals, grouping and read-across are among the most commonly used alternative approaches (ECHA 2017a and ECHA 2017b). Sector-specific legislation addressing specific uses of chemicals, such as the EU regulations on cosmetics (EC 1223/2009) and biocidal products (EU 528/2012), also allow for the use of grouping and read-across.

For chemicals in general the concept of grouping is well defined and established, being "the general approach for considering more than one chemical at the same time" (OECD 2014; ECHA 2008). Grouping can be achieved by following the category or the analogue approach (OECD 2014, ECHA 
2008, 2017a). A chemical category is a group of chemicals, the physico-chemical and (eco)toxicological and/or environmental fate properties of which are likely to be similar or follow a regular pattern as a result of structural similarity. Categories are usually established on the basis of coherent trends in physico-chemical properties that result in trends in (eco)toxicological and/or environmental fate properties. It is assumed that if several consistent trends can be identified within a category, the underlying category hypothesis is valid. Thus, it is important to include a sufficient number of chemicals to establish a category. If the number of chemicals is limited, the analogue approach can be used. In that case, trends in properties are not apparent. Based on structural similarity, read-across may still be applied but strongly depends on expert judgement and should therefore be substantiated by additional information. It should be noted that the distinction between the analogue and the category approach is not well-defined, being loosely based on the number of available chemicals in a group.

Once a category has been established or analogues have been identified on the basis of a specific grouping hypothesis, existing data must be linked to members of the group. Data gaps may then be filled by e.g. read-across, trend analysis or by establishing quantitative structure-activity relationships (QSARs). The term read-across is used when existing data, typically concerning one particular (eco)toxicological endpoint, linked to one or several source chemicals are used to estimate the same property of one or more target chemical(s). Read-across is more robust when applied in a category approach, as more data are available and apparent trends facilitate the read-across. Several in silico tools have been developed for supporting grouping and read-across (Patlewicz et al. 2017). However, fully automated chemical grouping is not possible. Several crucial steps rely on expert judgement, e.g. the identification of the key properties for decisions on similarity. Importantly, similarity should not be regarded as an absolute feature. Chemicals may be similar with respect to some, but not all, key properties. In addition, exceptions may exist even within an established group.

Structural similarity, which is the basis of grouping, may be based on various principles. Structural similarity for chemicals can rely on common functional groups, common precursors and/or the likelihood of common breakdown products or on a constant incremental change of the properties of interest across the group (OECD 2014, ECHA 2017a). In addition, the OECD definition explicitly mentions the common mode or mechanism of action (OECD 2014).

\section{General considerations on the grouping of NMs}

As summarized by Mech at al. 2018, the currently most advanced regulatory framework concerning NM grouping exists within REACH (EC 1907/2006), under which the European Chemicals Agency (ECHA) has already released a guidance document for NM grouping (ECHA 2017c). Within REACH, NMs are considered special forms of a chemical substance. The term 'nanoform' is used to 
distinguish different NMs of the same registered substance (ECHA 2017d). For the purpose of clarity and in the absence of a harmonized nomenclature across different EU chemical legislation we will use the term "nanoform" consistently in this manuscript as introduced in REACH on the $3^{\text {rd }}$ of December 2018 via the amended REACH annexes that specify information requirements concerning nanoforms of chemical substances (EU 2018/1881). The first two case studies of the practical process of grouping and read-across of nanoforms, concerning $\mathrm{TiO}_{2}$ and multi-walled carbon nanotubes following the workflow proposed by ECHA have been published (Lamon et al. 2018, Aschberger et al. 2019). Nevertheless, several challenges remain for the grouping of NMs.

The most urgent challenge to overcome is the unambiguous identification and characterization of nanoforms for the purpose of grouping. Defining a nanoform is much more complex than defining a non-nanoform of a chemical, as many more properties related to chemical identification and physical characterization are needed. For chemicals in general, chemical identification comprises the chemical composition, structural formula, degree of purity, and quantitative information on impurities or additives (EC 1907/2006) and might be challenging in some cases as well (ECHA 2017d). The description of nanoforms additionally requires information on the number based particle size distribution, surface functionalization or treatment, shape (aspect ratio, particle morphology) and specific surface area (EU 2018/1881). Furthermore, certain physical properties such as dissolution rate, state of agglomeration/aggregation and changes in surface chemistry are of specific interest as well but other properties such as surface reactivity may also be relevant (EU 2018/1881). The properties of NMs may be intrinsic, i.e. they depend on the NM itself, or extrinsic, i.e. they depend on the NM's interaction with the system or media in which it is tested. Therefore, NMs also need to be characterized in the relevant biological and environmental media used for toxicity testing.

The identification of key physico-chemical properties driving the toxicity of NMs, which is the basis for establishing grouping, is challenging for several reasons as recently summarized (Ribeiro et al. 2017, Drasler et al. 2017). Several physico-chemical properties have been identified as the most relevant ones for (eco)toxicity, i.e. surface area, chemical composition, surface chemistry, particle size and size distribution, surface charge, agglomeration state and crystalline structure (e.g. Orts-Gil et al. 2013, Ribeiro et al. 2017, Drasler et al. 2017). However, correlating specific physico-chemical properties to toxicity is not straightforward as a change in one property can influence NM fate, uptake, toxicokinetics and/or (eco)toxicity in a non-trivial manner. For instance, in several studies, smaller NMs have been found to be more toxic than larger size NMs (e.g. Pan et al. 2007, Karlsson et al. 2009), but opposite relationships have been found in some ecotoxicological studies (e.g., Ellegaard-Jensen et al. 2011) and generic interpretation of such findings still remains challenging. Size may directly affect toxicity and result in a higher surface area and surface reactivity per mass unit for smaller particles. Size and surface properties may also indirectly affect toxicity through altering 
toxicokinetics/dynamics, cellular uptake (often smaller NMs are more efficiently taken up by cells) or dissolution behaviour, in the case of partially soluble NMs (Shang et al. 2014). Care must be taken when interpreting in vitro studies, as size may also influence dosimetry and often only mass-based doses are compared, which results in the smaller particle sizes being dosed as higher particle numbers per mass unit (Drasler et al. 2017). Some studies have also found smaller particles to be agglomerated to a larger extent than their larger counterparts, which then resulted in a decreased cellular uptake (Halamoda-Kenzaoui et al. 2017). Therefore, carefully made decisions on test item preparation and exposure characterization are critical (Hartman et al., 2015) and projects like NANoREG made substantial effort to harmonize such procedures to improve comparability between laboratories (refer to: https://www.rivm.nl/en/about-rivm/mission-and-strategy/internationalaffairs/international-projects/nanoreg/work-package//wp-2-synthesis-supplying-andcharacterization).

Thus, establishing grouping approaches for NMs remains laborious and conventional structureactivity relationships based on one or only a few structure properties are, generally speaking, not applicable to NMs (Landsiedel 2016).

To identify and select the most useful and promising approaches for grouping to be applied and possibly extended within the EU H2020 NanoReg2 project, which worked on the "Development and implementation of Grouping and Safe-by-Design approaches within regulatory frameworks", we performed a systematic literature search in PubMed, yielding 273 publications (as per $25^{\text {th }}$ of January 2019) using the following keywords:

1) "grouping" and "nanomaterials" or "nanoparticles"

2) "categorization" and "nanomaterials" or "nanoparticles"

3) "read-across" and "nanomaterials" or "nanoparticles"

4) "QSAR" and "nanomaterials" or "nanoparticles"

The most relevant publications, in order to develop and implement grouping and Safe by Design $(\mathrm{SbD})$ approaches within regulatory framework, were identified based on expert judgment of NanoReg2 partners. This resulted in a list of 37 papers, which were subsequently assessed in detail considering the following criteria:

1) Does the approach clearly describe the criteria and parameters for grouping? What are these criteria/parameters?

2) Has the approach been tested, verified or validated? How?

3) Why is this approach relevant? How and for which purpose can it be applied?

It should be noted that to date only a few large and comprehensive frameworks for NM grouping have been developed. However, there are a larger number of grouping approaches and conceptual 
papers available that provide useful input for how to approach NM grouping. In our screening process we identified 20 different published strategies, approaches, frameworks and opinions on how NM grouping should be constructed that will be discussed in detail below. We summarize the criteria used, the advantages and disadvantages of each approach, including a statement of the applicability for regulatory purposes. It is worth noting that each of the comprehensive frameworks can be applied according to a category or analogue approach, depending on the number of available source materials.

\section{Strategies for NMs risk assessment including NM grouping}

Many of the current concepts for NM grouping have evolved from general strategies for NM hazard and risk assessment. Thus, the publications that are discussed in this section concern NM testing and risk assessment strategies in general but also include information that is relevant and useful for NM grouping. Oomen et al. have published a comprehensive review on risk assessment frameworks for NMs (Oomen et al. 2018) and evidenced the needs for efficient NM risk assessment. The NM hazard and risk assessment strategies most relevant for grouping purposes (according to expert judgment of NanoReg2 partners) are summarized in Table 1.

Table 1 Overview of NM hazard and risk assessment strategies

\begin{tabular}{|c|c|c|}
\hline Strategy & Focus & Key Features \\
\hline RCC 2014 & $\begin{array}{l}\text { Prioritization Strategy } \\
\text { Human health }\end{array}$ & $\begin{array}{l}\text { Exposure route } \\
\text { Physico-chemical identity (solubility, shape, } \\
\text { aspect ratio) }\end{array}$ \\
\hline $\begin{array}{l}\text { Stone et al. } 2014 \\
\text { Developed in the EU FP7 } \\
\text { ITS Nano project }\end{array}$ & $\begin{array}{l}\text { Testing Strategy } \\
\text { Human health }\end{array}$ & $\begin{array}{l}\text { Physico-chemical identity } \\
\text { Exposure identity } \\
\text { Hazard identity }\end{array}$ \\
\hline $\begin{array}{l}\text { Bos et al. } 2015 \\
\text { Developed in the EU FP7 } \\
\text { MARINA project }\end{array}$ & $\begin{array}{l}\text { Risk assessment strategy } \\
\text { Human health } \\
\text { Environment }\end{array}$ & $\begin{array}{l}\text { Physico-chemical identity } \\
\text { Exposure } \\
\text { Fate/Kinetics } \\
\text { Hazard (human and ecotoxicity) }\end{array}$ \\
\hline $\begin{array}{l}\text { Dekkers et al. } 2016 \\
\text { Developed in the EU FP7 } \\
\text { NANoREG project }\end{array}$ & $\begin{array}{l}\text { Risk assessment strategy } \\
\text { Human health }\end{array}$ & $\begin{array}{l}\text { Physico-chemical identity } \\
\text { Exposure potential } \\
\text { Dissolution } \\
\text { Transformation } \\
\text { Accumulation } \\
\text { Hazard (human and ecotoxicity) }\end{array}$ \\
\hline Hund-Rinke et al. (2015) & $\begin{array}{l}\text { Risk assessment strategy } \\
\text { (following a tiered life cycle } \\
\text { oriented approach) } \\
\text { Environment }\end{array}$ & $\begin{array}{l}\text { Physico-chemical identity } \\
\text { Exposure } \\
\text { Dissolution } \\
\text { Transformation } \\
\text { Accumulation } \\
\text { Hazard (ecotoxicity) }\end{array}$ \\
\hline $\begin{array}{l}\text { Siegrist et al. (2018) } \\
\text { Developed in the EU } \\
\text { H2020 NanoReg2 } \\
\text { project }\end{array}$ & $\begin{array}{l}\text { Hazard assessment strategy } \\
\text { Human health } \\
\text { (Pre-clinical safety evaluation of } \\
\text { injectable nanoparticles) }\end{array}$ & $\begin{array}{l}\text { Physico-chemical identity } \\
\text { Bio-interaction capacity } \\
\text { Hazard (human) }\end{array}$ \\
\hline
\end{tabular}


The U.S.-Canada Regulatory Cooperation Council (RCC) developed an approach to identify novel NMs of concern for human health considering different exposure routes (RCC 2014). This approach suggests that solubility, shape and aspect ratio are important triggers for toxicological concern.

The EU FP7 project ITS-NANO (2012-2013) was one of the first projects that aimed to develop an overarching Intelligent Testing Strategy (ITS) for the risk assessment of NMs (Stone et al. 2014). The outcomes of ITS-NANO describe three elements of NM risk assessment - physico-chemical, exposure and hazard - and connect to each of them a corresponding "identity", generated by the information required for that element of the assessment. The physico-chemical, exposure and hazard identities are defined respectively as "the dynamic pattern of physical and chemical characteristics associated with one or several specified NMs during their life cycle", "the pattern of concentrations of one or more NMs in different matrices (air, liquid or solid) and as a function of duration and variability over time during their life cycle", and "the pattern of biological responses associated with one or several specified NMs" (Stone et al. 2014). Grouping based on such identities was postulated. Furthermore, for each of the elements, research needs for the short-term ( $<5$ years), mid-term (5-10 years), longterm (10-15 years) and distant (> 15 years) future were identified. The ITS-NANO approach laid the basis for many other grouping approaches, including what are now known as the "what they are", "where they go" and "what they do" pillars used in several NM grouping approaches.

The MARINA risk assessment strategy (RAS) (Bos et al. 2015) built upon and extended the ITS-NANO approach to establish a general and flexible strategy for obtaining data to satisfy specific needs. It consists of two phases. In the "problem framing phase", all available data are collected and evaluated, relevant exposure scenarios are identified and the goals of the second phase are set. In the "risk assessment phase", an iterative risk characterization is performed. For risk characterization, data gaps are identified and filled using defined tools and the obtained data is evaluated. Tools for data gathering are collected in three toolboxes, focusing on exposure, fate/kinetics and hazards, respectively. The tools support data evaluation in both phases and data gathering in the second phase. A fourth toolbox on risk characterization can be used to identify relevant exposure scenarios in the first phase and for risk characterization in the second phase. Within the MARINA RAS, several possibilities for NMs grouping based on similar physico-chemical properties, exposure (justified for example by similar applications and/or processes), or hazard (using for example the groups derived by Arts et al. 2015) are suggested, as reported later on.

The NANoREG risk assessment strategy (Dekkers et al. 2016) proposes a strategy that refers to several nanospecific properties influencing exposure to and hazards of NMs. Six major elements for NM risk assessment are identified: the exposure potential, dissolution (including dissolution rate), NM transformation, NM accumulation in the human body, genotoxicity and immunotoxicity of NMs. 
This approach has two main objectives, 1) to prioritize the most hazardous NMs, which is done in the first phase, and 2) to identify the most important information needed for risk assessment, which is addressed in subsequent phases. In the first phase, NMs are categorized according to their physicochemical properties (such as size, shape and dissolution rate in water) into three categories: category 1 containing potentially hazardous NMs for which a detailed nano-specific assessment needs to be performed, category 2 containing NMs that can be addressed using a non-nanospecific risk assessment strategy, and category 3 containing NMs that need further evaluation. The NMs in category 3 will enter the second phase. In a second step of the first phase, the applications of NMs are prioritized according to exposure potential (exposure ranking) and hazard potential (hazard ranking). The exposure ranking is obtained by considering the production volume of the NM, the processes and operational conditions relevant for occupational exposure, or whether/how NMs are embedded in a matrix throughout the entire life cycle relevant to consumer exposure. The hazard ranking is based on a) the classification of NMs concerning carcinogenic, mutagenic and reprotoxic (CMR) properties, allergenic potential or irritation and b) potential NM reactivity, as predicted by band gap analysis (metals and metal oxides) or by assays that measure NM reactivity (e.g. the potential of a NM to form reactive oxygen species, ROS). The exposure and hazard rankings are then combined to categorize NM applications in subgroups indicating a high, medium or low potential to cause harmful effects. In the second phase, more detailed information for NMs that need further evaluation is collected, involving exposure pattern, physical form and NM aerosol concentrations (for occupational exposure) or amounts available for exposure (for consumer exposure), dissolution rate in relevant media, translocation and absorption into the body, aggregation and agglomeration, cellular uptake, in vitro cytotoxicity, ROS generation, cytokines induction, in vitro skin and eye irritation, cell transformation assay and in vitro genotoxicity.

The frameworks described above mainly focus on human health risk assessment, although some of them, such as the MARINA RAS (Bos et al. 2015), to a certain extent also cover environmental risks. Hund-Rinke et al. 2015 established the currently most advanced framework for assessing environmental risks. This is a tiered, life cycle oriented approach considering production, transport and distribution to the user, use, and waste management. The specific environmental compartment in which the NM could be released is first identified. Tier 0 consists of the assessment of durability: if the NM preserves its nano-properties in the specific environment compartment, Tier 1 in which fate and effects must be determined is performed. The result of Tier 1 is a risk quotient. If the risk quotient is below 1 , acceptable risk for the initial compartment can be assumed and no further (more sophisticated) risk assessment for the initial compartment is needed. For a risk quotient exceeding 1 , the risk for the initial compartment may not be negligible and, thus, a refinement at Tier 2 is needed. If there is a possibility of NM transportation to a secondary compartment, further evaluation of fate 
and effect in that compartment is also required. In addition, Hund-Rinke et al. have developed a concept for the grouping of NMs according to their ecotoxicological effects on algae, daphnids and fish embryos (Hund-Rinke et al. 2018), which will be discussed later.

Siegrist et al. 2018 published a preclinical hazard evaluation strategy (HES) for injectable nanoparticles with intended medicinal use. This strategy proposes a three-tiered approach for hazard classification by mainly considering physico-chemical characterization and the nano-biointeractions. Four hazard categories based on cellular uptake and intracellular persistence of a nanoparticle are described: low persistence, low uptake (class I), low persistence, high uptake (class II), high persistence, low uptake (class III), and high persistence, high uptake (class IV). Although some examples with published data on several nanoparticles are given in the publication, the approach still needs testing and validation with a larger set of particles to prove its applicability.

\section{NM categorization/grouping approaches for occupational safety}

Several grouping approaches for NMs have been developed specifically in the context of occupational safety. They focus on inhalation exposure, which is of highest concern for occupational settings, and allow for quick prioritization, screening and ranking of NMs (Table 2). Strictly speaking, these approaches are not grouping approaches as defined by OECD or ECHA in which data gaps are filled in an endpoint-specific manner (OECD 2014; ECHA 2008), but categorization approaches: they arrange NMs in pragmatic groups for which different control strategies are proposed.

Table 2 Overview of NM grouping approaches for occupational safety

\begin{tabular}{|l|l|l|l|}
\hline Approach & Groups & Key criteria & Benchmarks \\
\hline $\begin{array}{l}\text { BSI } \\
\text { (BSI 2007) }\end{array}$ & $\begin{array}{l}\text { i) fibres } \\
\text { ii) toxic (CMAR)* particles } \\
\text { iii) insoluble, non-CMAR* particles } \\
\text { iv) soluble particles (not assigned } \\
\text { to other group) }\end{array}$ & $\begin{array}{l}\text { NM solubility } \\
\text { toxicity of bulk } \\
\text { counterparts }\end{array}$ & \\
\hline $\begin{array}{l}\text { NIOSH } \\
\text { (Kuempel et al. } \\
\text { 2012) }\end{array}$ & $\begin{array}{l}\text { i) soluble, toxic particles } \\
\text { ii) poorly soluble, low toxicity } \\
\text { particles } \\
\text { iii) poorly soluble, toxic particles } \\
\text { iv) fibres }\end{array}$ & $\begin{array}{l}\text { NM solubility } \\
\text { toxicity of bulk } \\
\text { counterparts } \\
\text { Mode of Action }\end{array}$ & $\begin{array}{l}\text { i) } \mathrm{ZnO} \text {, CuO }_{\text {ii) } \mathrm{TiO}_{2} \text {, carbon black }} \\
\text { iii) crystaline silica, NiO, } \\
\mathrm{Cr}_{2} \mathrm{O}_{3} \\
\text { iv) carbon nanotubes, } \\
\text { carbon nanofibres }\end{array}$ \\
\hline $\begin{array}{l}\text { BAuA } \\
\text { (BAuA 2013, } \\
\text { Gebel et al. 2014, } \\
\text { BAuA 2015) }\end{array}$ & $\begin{array}{l}\text { i) soluble particles } \\
\text { ii) biopersistent toxic particles } \\
\text { iii) biopersistent non- toxic } \\
\text { particles } \\
\text { iv) biopersistent fibres }\end{array}$ & $\begin{array}{l}\text { NM solubility } \\
\text { biopersistence } \\
\text { toxicity of bulk } \\
\text { counterparts }\end{array}$ & \\
\hline
\end{tabular}

* carcinogenic, mutagenic, asthmagenic or reprotoxic

The British Standards Institution (BSI) categorization scheme categorizes NMs into four groups, taking into account solubility and toxicological effects of the corresponding non-nano (i.e. bulk) materials (BSI 2007). It distinguishes between i) fibrous NMs, ii) NMs whose non-nanosized 
counterparts are already classified as carcinogenic, mutagenic, asthmagenic or reprotoxic (CMAR), iii) insoluble or poorly soluble NMs that are categorized neither as fibrous nor as CMAR, iv) soluble NMs not assigned to any other category. For each group a control strategy is suggested to limit exposure during generic tasks such as deliberate aerosol formation, transferring, mixing, scooping of dry material, filling of suspensions or maintenance and cleaning (BSI 2007).

A similar categorization approach has been proposed by the National Institute for Occupational Safety and Health (NIOSH) (Kuempel et al. 2012). It extends the BSI approach by taking into account the Mode of Action (MoA). For each MoA, the hazard is evaluated and benchmark materials are identified for which full quantitative risk assessment, occupational exposure limits (OELs) and exposure control bands are available. NMs with limited data are then classified based on comparisons to the benchmark materials (Kuempel et al. 2012). The NIOSH categorization approach distinguishes between 1) NMs with higher solubility that release toxic ions (benchmarks: e.g. ZnO and $\mathrm{CuO}), 2$ ) poorly soluble particles of low toxicity, which are NMs whose surface area determines their toxicity after inhalation (benchmarks: e.g. $\mathrm{TiO}_{2}$ and carbon black), 3) poorly soluble NMs with high toxicity whose surface reactivity determines their toxicity (benchmarks: e.g. crystalline $\mathrm{SiO}_{2}, \mathrm{NiO}$ and $\left.\mathrm{Cr}_{2} \mathrm{O}_{3}\right)$, 4) fibrous NMs whose toxicity is determined by the biopersistence of the fibres and their migration to the pleura, either by interference with normal cell division or by genotoxicity (benchmarks: e.g. carbon nanotubes and carbon nanofibres). When a NM fits into one of these groups the OELs of the benchmark material can be applied and the control banding system can be used to reduce exposure.

The German Federal Institute for Occupational Safety and Health (BAuA) follows a very similar approach (BAuA 2013 and 2015, Gebel et al. 2014). It classifies NMs in the following four groups used for determining the protective measures: i) soluble NMs, ii) biopersistent NMs with specific toxicological properties (e.g. release of toxic ions), iii) biopersistent NMs without specific toxicological properties, and iv) biopersistent, fibrous NMs.

\section{Control Banding Tools and their NM categorization approaches}

Like the categorization/grouping approaches for occupational safety, risk categorization and control banding tools are not grouping approaches according to the definitions by OECD or ECHA (OECD 2014; ECHA 2008). They categorise the scale of estimated risk and place it in one of several levels or bands. Liguori et al. (2016) made a comprehensive analysis of the input and output parameters in the current risk categorization and control banding tools intended for occupational risk management. Some tools also consider consumer and environmental exposure scenarios. To give examples of different approaches, this paper summarises four fundamentally different risk tools (see Table 3). It is important to note that the input parameters in control banding tools were selected to provide 
automated risk scaling. It means that risk scaling procedures are made for grouping and that they are relevant for the identification of parameters significant for regulatory accepted NM grouping approaches as described in the following section.

Table 3 Overview of selected control banding tools and NM categorization approaches

\begin{tabular}{|c|c|c|c|}
\hline Approach & Focus & Categories & Key criteria \\
\hline $\begin{array}{l}\text { NanoSafer } \\
\text { V1.1 } \\
\text { (Jensen et al. } \\
\text { 2014; Liguori } \\
\text { et al. 2016) }\end{array}$ & $\begin{array}{l}\text { Occupational } \\
\text { Consumer } \\
\text { Environment }\end{array}$ & $\begin{array}{l}4 \text { Hazard bands (HB) } \\
\text { H1: Very low toxicity } \\
\ldots \\
\text { H4: Very high toxicity } \\
5 \text { Exposure bands (EB): } \\
\text { EB1: No or very low exposure } \\
\text { potential } \\
\ldots \\
\text { EB5: Very high exposure } \\
\text { potential } \\
5 \text { risk levels (RL), } \\
\text { RL1: Very low toxicity and low } \\
\text { exposure potential } \\
\ldots \\
\text { RL5: Very high toxicity and/or } \\
\text { very high exposure potential }\end{array}$ & $\begin{array}{l}\text { Hazard: physico-chemical properties } \\
\text { (water solubility, aspect ratio, } \\
\text { presence of coatings), hazard and OEL } \\
\text { of NM or the nearest bulk analogue, } \\
\text { specific surface area, skeletal density. } \\
\text { Exposure: Estimation of near-field and } \\
\text { far-field exposure potential based on } \\
\text { measured or default dustiness data, } \\
\text { use rates or release rates and } \\
\text { contextual information }\end{array}$ \\
\hline $\begin{array}{l}\text { ANSES Tool } \\
\text { (Riediker et al. } \\
\text { 2012) }\end{array}$ & Occupational & $\begin{array}{l}5 \text { Hazard bands (HB), } \\
\text { HB1: Very low - no significant } \\
\text { health risk } \\
\text {.. } \\
\text { HB5: Very high- severe hazard }\end{array}$ & $\begin{array}{l}\text { Hazard: CLP* classifications (NM \& } \\
\text { bulk) Emission potential: } \\
\text { Four categories defined: } \\
\text { Solid: materials containing NMs; } \\
\text { Liquid: suspension of nanoobjects or } \\
\text { aggregates/agglomerates; } \\
\text { Powder: nano-objects and/or } \\
\text { aggregates/ agglomerates; } \\
\text { Aerosol: liquid or solid suspension. }\end{array}$ \\
\hline $\begin{array}{l}\text { Swiss } \\
\text { Precautionary } \\
\text { Matrix } \\
\text { (SMP 2013, } \\
\text { 2018) }\end{array}$ & $\begin{array}{l}\text { Occupational } \\
\text { Consumer } \\
\text { Environment }\end{array}$ & $\begin{array}{l}\text { Class A: no further/ specific } \\
\text { actions needed } \\
\text { Class B: specific precautionary } \\
\text { measures needed }\end{array}$ & $\begin{array}{l}\text { Hazard: NM stability (dissolution rate } \\
\text { in physiological, environmental } \\
\text { media), reactivity (i.e. redox, catalytic } \\
\text { activity, ROS formation, inflammation) } \\
\text { Human exposure: carrier/matrix } \\
\text { material, NM amounts, frequency of } \\
\text { handling } \\
\text { Environmental release: carrier/matrix } \\
\text { material, NM amounts in products, in } \\
\text { waste }\end{array}$ \\
\hline $\begin{array}{l}\text { NanoRiskCat } \\
\text { (Hansen et al. } \\
2011,2014 \text { ) }\end{array}$ & $\begin{array}{l}\text { Occupational } \\
\text { Consumer } \\
\text { Environment }\end{array}$ & $\begin{array}{l}\text { Coloured dots (five } \\
\text { categories) } \\
\text { - worker exposure } \\
\text { - consumer exposure } \\
\text { - environ. exposure } \\
\text { - human hazard } \\
\text { - environ. hazard } \\
\text { Colour code } \\
\text { - red (high) } \\
\text { - yellow (medium) } \\
\text { - green (low) }\end{array}$ & $\begin{array}{l}\text { Exposure: categories of use (as } \\
\text { defined in REACH) and NM } \\
\text { incorporation in products } \\
\text { Hazard: CLP* classification (NM \& } \\
\text { bulk) }\end{array}$ \\
\hline
\end{tabular}


\begin{tabular}{|l|l|l|}
\hline & - grey (unknown) & \\
\hline * Regulation on classification labelling and packaging of substances and mixtures (EC 1272/2008)
\end{tabular}

NanoSafer is a web-based control-banding and risk management tool for manufactured NMs (Jensen et al. 2014) available at www.nanosafer.org. The tool was developed for assisting small and mediumsized companies with limited or no experience of producing or working with NMs and/or with insufficient resources to perform a full precautionary risk assessment. The input parameters cover categories such as identification data (material name and other identifiers), physico-chemical properties from technical data sheets (size, morphology, coating, specific surface area, relative (skeletal) density, water solubility, dustiness if applicable), bulk or NM safety data sheet information (OEL or limit values and hazard phrases) and the contextual information (process and activity information, room size, ventilation rate) for exposure assessment (Liguori et al, 2016). In several cases default values can be used when users do not have the information required. Case-specific exposure scaling is combined with specific NM hazard grouping and scaling and the resulting risk levels are expressed as control bands. Five risk levels (RL) are described, ranging from RL1 with very low hazard and low exposure potential to RL5 with very high hazard and/or moderate to very high exposure potential. Bulk similarity is considered for hazard when the NM is water-soluble (solubility $>1 \mathrm{~g} / \mathrm{L}$ ) while the volume-specific surface area is used for scaling of the bulk OEL, if no NM-specific limit value is known. Fibres complying with the WHO definition of insoluble fibres are by default considered compounds with potential high toxicity. Lack of information results in increased precaution in the scaling of potential risk, but a minimum level of information is required. Each RL is associated with standard guidance on risk management and further recommendations via e-learning tools, and good practice guidance.

ANSES has also developed a Control Banding tool aimed at small and medium-sized enterprises. It builds on a hazard classification developed from a few very fundamental physico-chemical and toxicological properties of NMs (Riediker et al. 2012). The input data can be collected at the workplace through observation of actual work and as available toxicology data, material and matrix properties and process characteristics. Four categories of physical forms were defined for the purpose of this approach: Solid materials containing NMs or having a surface that is nanostructured or covered with nanoparticles; Liquids, suspensions of free nano-objects or aggregates /agglomerates of nano-objects smaller than $100 \mathrm{~nm}$ in a liquid medium; Powders, free nano-objects and/or aggregates/agglomerates of nano-objects; and Aerosols of liquid or solid suspension (free nanoobjects or aggregates/agglomerates of nano-objects smaller than $100 \mathrm{~nm}$ in a gas including air). The hazard bands are related to existing technical documentation (labelling, product classification) or to various criteria for toxicity described in the literature. 
The Swiss Precautionary Matrix (SMP 2013, 2018) is a web-based tool for identifying potential risks to workers, consumers and the environment arising from NMs through their whole life cycle, including the research and development phase, production, use and disposal. The aim is to highlight needs for specific actions, i.e. precautionary measures, not to perform a full nano-specific risk assessment. The user is guided through different input queries to collect information about the NM of interest, including the potential effects, exposure and release into the environment. In order to determine potential NM effects, the stability (dissolution rate) in physiological and environmental media and the cell-free (redox potential, photocatalytic reactivity and biological oxidative damage) as well as the cellular reactivity (ROS formation, inflammation, glutathion reduction, protein carbonylation) is evaluated (SPM 2018). The potential human exposure is estimated by taking into account the carrier/matrix material, the amount of NMs handled by employees or downstream users and the frequency of handling. The potential release into the environment is evaluated by taking into account the carrier/matrix material, the total amount of NMs in specific products, and the NM amount in waste (i.e. wastewater, exhaust gases, solid waste). Based on the estimated risks, the NMs are classified in two categories: NMs which do not need further or specific actions (class A) and NMs for which specific precautionary measures should be taken (class B). Even if this matrix does not provide a full risk assessment, the results are indicative of risks and support decision-making in a very simple and quick manner.

NanoRiskCat (NRC) was initially developed for the Danish Environmental Protection Agency (DEPA) as a risk categorization tool to identify nano-enabled products, which would require further information and documentation (Hansen et al. 2011, Hansen et al. 2014) and is available at www.nanodb.dk/da/nanoriskcat/. The tool can assist companies and regulators in making a first-tier assessment of the hazard and exposure potential of products containing NMs. It uses information obtained from the scientific literature. Instead of calculating a risk, the tool visualizes the results in five colour-coded dots: the first three represent the potential exposures for professional end-users, consumers, and environment, and the last two the hazard potentials for humans and the environment. The potential exposure is evaluated by a simple yes/no answer to the applicability of the 27 work processes, 40 product categories and 51 technical functions defined and described by REACH (Hansen et al. 2007). Hazard potential is primarily evaluated on the basis of the classification according to the regulation on Classification Labelling and Packaging (EC 1272/2008), of the NMs and their corresponding bulk materials, where available. When considering hazard potentials for humans and the environment nano-specific qualifiers are then considered. Four different colours are used for each of the five dots to classify the potential for exposure or hazard as high (red), medium (yellow), low (green), or unknown (grey). The exposure potential assessment builds on and extends a categorization approach published by Hansen et al. (2007), which distinguishes three product 
categories: nanostructured materials (category I), nanostructured surfaces (category II) and solid materials containing nanoparticles (category III). These categories can be further sub-divided in 9 sub-categories. The hazard potential is derived from nine physico-chemical properties: chemical composition, size, shape, crystal structure, surface area, surface chemistry, surface charge, solubility and adhesion. When lack of data is prominent, the result is a "grey" dot indicating unknown hazard or exposure. NanoRiskCat assessments have been made on more than 3000 products in the Danish Nanodatabase (http://nanodb.dk/). Thus, a user or a manufacturer can easily find their product or a similar one and quickly see a preliminary score.

\section{NM Grouping frameworks}

Five specific and comprehensive frameworks (Table 4) for NM grouping according to the definition of grouping of OECD and ECHA (OECD 2014; ECHA 2008) have been identified and are discussed in detail in this section. In addition, a joint ECHA/ JRC/ RIVM publication, synthesising several approaches, is also discussed. This publication was the basis for the guidance document on NM grouping released by ECHA (ECHA 2017c). 
Table 4 Overview of specific frameworks developed for NM grouping

\begin{tabular}{|c|c|c|c|c|}
\hline Approach & Categories & Key criteria & Opportunities & Limitations \\
\hline RCC (RCC 2013) & $\begin{array}{l}\text { 1) Carbon nanotubes, } \\
\text { 2) Inorganic carbon, } \\
\text { 3) Metal oxides and metalloid } \\
\text { oxides, } \\
\text { 4) Metals, metal salts, metalloids, } \\
\text { 5) Semi-conductor materials, } \\
\text { quantum dots, } \\
\text { 6) Organics, } \\
\text { 7) Other classes (e.g. metal alloys, } \\
\text { nanoclays, tubes of metals/ } \\
\text { metalloids, bionanomaterials) }\end{array}$ & Chemical identity & $\begin{array}{l}\text { It stresses the role of chemical identity in the } \\
\text { identification of similar NMs; it identifies } \\
\text { categories easy to understand and to apply to } \\
\text { real cases; it identifies some important } \\
\text { intrinsic properties identifying NMs with a } \\
\text { similar behaviour }\end{array}$ & $\begin{array}{l}\text { The categories are identified by } \\
\text { expert-judgement and not by } \\
\text { well-defined criteria; hybrid } \\
\text { NMs (i.e. NMs of multiple } \\
\text { composition) are not considered } \\
\text { in the analysis; assays and } \\
\text { threshold values are not } \\
\text { addressed; extrinsic parameters } \\
\text { and MoA are not taken into } \\
\text { account }\end{array}$ \\
\hline $\begin{array}{l}\text { RIVM (Sellers et al. } \\
\text { 2015) }\end{array}$ & & $\begin{array}{l}\text { Chemical identity, intrinsic } \\
\text { and extrinsic properties, } \\
\text { reactivity }\end{array}$ & $\begin{array}{l}\text { It identifies important intrinsic and extrinsic } \\
\text { properties; it takes into account that the NMs } \\
\text { properties vary with the medium considered; } \\
\text { it suggests measuring properties, such as } \\
\text { dissolution and reactivity, in relevant } \\
\text { biological media; it proposes a testing } \\
\text { strategy based on hypotheses; it applies the } \\
\text { testing strategy to several human health } \\
\text { endpoints relevant for REACH regulation }\end{array}$ & $\begin{array}{l}\text { It does not define specific } \\
\text { groups, but rather presents a } \\
\text { general strategy; threshold } \\
\text { values are not included; } \\
\text { grouping is limited to specific } \\
\text { toxicological endpoints, verified } \\
\text { only in } 2 \text { theoretical case studies }\end{array}$ \\
\hline $\begin{array}{l}\text { DF4nano Grouping } \\
\text { (Arts et al. 2015) }\end{array}$ & $\begin{array}{l}\text { 1) Soluble NMs, } \\
\text { 2) Biopersistent HAR NMs, } \\
\text { 3) Passive NMs } \\
\text { 4) Active NMs }\end{array}$ & $\begin{array}{l}\text { Intrinsic and extrinsic } \\
\text { properties; Use, release, } \\
\text { exposure route; } \\
\text { Biopersistence; } \\
\text { Uptake, biodistribution; } \\
\text { reactivity (cellular and } \\
\text { apical toxic effects) }\end{array}$ & $\begin{array}{l}\text { It identifies important intrinsic and extrinsic } \\
\text { properties of NMs; it suggests unambiguous } \\
\text { criteria for grouping; it clearly defines groups; } \\
\text { it indicates suitable assays for a testing } \\
\text { strategy and suggests threshold values; it has } \\
\text { been applied in several case studies }\end{array}$ & $\begin{array}{l}\text { Limited to inhalation route of } \\
\text { exposure; active NMs are not } \\
\text { deeper investigated and } \\
\text { assigned to subgroups; the } \\
\text { groups do not correlate to } \\
\text { human health endpoints } \\
\text { relevant for EU regulations }\end{array}$ \\
\hline $\begin{array}{l}\text { MARINA grouping and } \\
\text { read- across approach }\end{array}$ & & $\begin{array}{l}\text { Chemical identity; intrinsic } \\
\text { and extrinsic properties; } \\
\text { reactivity }\end{array}$ & $\begin{array}{l}\text { It identifies important intrinsic and extrinsic } \\
\text { properties of NMs; it integrates the concepts } \\
\text { of grouping and read-across in several steps }\end{array}$ & $\begin{array}{l}\text { No assays and threshold values } \\
\text { are suggested such that } \\
\text { applicability remains unclear }\end{array}$ \\
\hline
\end{tabular}




\begin{tabular}{|c|c|c|c|c|}
\hline (Oomen et al. 2015) & & & of the risk assessment process & \\
\hline Hund-Rinke et al. 2018 & $\begin{array}{l}\text { 1. Ion releasing NMs with } \\
\text { DMPO*/CPH** reactivity and other } \\
\text { morphology. } \\
\text { 2. Ion releasing NMs with } \\
\text { DMPO/CPH reactivity, wire } \\
\text { 3. Ion releasing NMs without } \\
\text { DMPO/CPH reactivity, wire } \\
\text { 4. Ion releasing NMs without } \\
\text { DMPO/CPH reactivity, other } \\
\text { morphology: } \\
\text { 5. Non-ion releasing NMs, with } \\
\text { DMPO/CPH reactivity and other } \\
\text { morphology } \\
\text { 6. Non-ion releasing NMs, without } \\
\text { DMPO/CPH reactivity and other } \\
\text { morphology }\end{array}$ & $\begin{array}{l}\text { Ecotoxicity of bulk } \\
\text { material, lon release, } \\
\text { Reactivity and } \\
\text { Morphology/Size }\end{array}$ & $\begin{array}{l}\text { Only environmental approach for grouping of } \\
\text { NMs. The scheme is based on a set of } \\
\text { systematically acquired data. It is verified with } \\
\text { a different set of NMs. }\end{array}$ & $\begin{array}{l}\text { Specifications and threshold } \\
\text { values with regard to the } \\
\text { properties solubility, reactivity } \\
\text { and morphology need to be } \\
\text { determined. Scheme valid only } \\
\text { for metal and metal oxides }\end{array}$ \\
\hline $\begin{array}{l}\text { ECHA, JRC and RIVM } \\
\text { joint document (ECHA, } \\
\text { JRC, RIVM 2016) } \\
\text { ECHA guidance for NM } \\
\text { grouping (ECHA 2017c) }\end{array}$ & $\begin{array}{l}\text { Conceptually all substances in } \\
\text { nanoform }\end{array}$ & $\begin{array}{l}\text { Intrinsic and extrinsic } \\
\text { properties; } \\
\text { Reactivity (Biological and } \\
\text { Photoreactivity) }\end{array}$ & $\begin{array}{l}\text { It provides a general strategy for sharing data } \\
\text { between nanoforms; it indicates key physico- } \\
\text { chemical parameters which should be } \\
\text { considered. There is a direct link to existing } \\
\text { EU-regulation (REACH). }\end{array}$ & $\begin{array}{l}\text { It is just a conceptual approach, } \\
\text { without any practical } \\
\text { information on assays and } \\
\text { thresholds } \\
1\end{array}$ \\
\hline
\end{tabular}

1 *DMPO: Hydroxyl radical generation measured according to Shi et al. (2003) and after UV irradiation according to Lipovsky et al. (2009) and Lipovsky et al. (2012).

${ }^{* *} \mathrm{CPH}$ : a possible (surface) reactivity 
The approach developed by the U.S.-Canada Regulatory Cooperation Council (see https://www.canada.ca/en/health-canada/corporate/about-health-canada/legislationguidelines/acts-regulations/canada-united-states-regulatory-cooperation-council.html) categorizes NMs based on similar chemical compositions (RCC 2013). It aims to distinguish between NMs, which can be assessed as chemicals in general due to sufficient similarity to the corresponding nonnanomaterial, and NMs, which require a closer examination based on their differences from the corresponding non-nanomaterial or NMs, which do not have a corresponding non-nanomaterial. The grouping approach focuses on the latter group of NMs and categorizes them on the basis of chemical composition (see Table 4). These categories are not fixed and can be changed or refined if necessary. The relevant intrinsic physico-chemical parameters, which allow identifying similar materials that can be used to obtain analogue or read-across information, are defined and reported in Table 5. Extrinsic parameters are not taken into consideration in this categorization scheme.

Table 5 RCC categorization scheme based on similarities in chemical composition

\begin{tabular}{|l|l|}
\hline Categories & Relevant intrinsic parameters defining similar NMs \\
\hline Carbon nanotubes & $\begin{array}{l}\text { Number of walls, diameter, length, capped/uncapped, chirality, } \\
\text { surface chemistry and surface modification }\end{array}$ \\
\hline Inorganic Carbon & $\begin{array}{l}\text { Number of layers, size, shape, chemical modifications, surface } \\
\text { chemistry, surface modification }\end{array}$ \\
\hline Metal oxides and metalloid oxides & $\begin{array}{l}\text { Size and shape, composition, solubility, crystal structure, surface } \\
\text { chemistry, surface modification }\end{array}$ \\
\hline Metals, metal salts, metalloids & $\begin{array}{l}\text { Size and shape, composition, solubility, oxidation states, surface } \\
\text { chemistry, surface modification }\end{array}$ \\
\hline Semi-conductor quantum dots & $\begin{array}{l}\text { Size and shape, core-shell composition, solubility, surface chemistry, } \\
\text { surface modification }\end{array}$ \\
\hline Organics & Size and shape, surface chemistry, surface modification, crystallinity \\
\hline Other classes & $\begin{array}{l}\text { e.g. metal alloys, nanoclays, tubes of metals/ metalloids, } \\
\text { bionanomaterials }\end{array}$ \\
\hline
\end{tabular}

The approach proposed by the Dutch National Institute for Public Health and the Environment (RIVM) takes into account the transformation of the NMs by measuring their stability and reactivity in relevant biological media (Sellers et al. 2015). The first step of this approach focuses on assessing the intrinsic physico-chemical characteristics of the material as required by REACH ("chemical identity") as well as a few additional particle-related properties ("particle characteristics"). In the second step, the stability and reactivity of the NM in the relevant biological medium are assessed. Two behaviour categories are defined and several key parameters are identified, although not all of them can be easily measured, e.g. "transport behaviour" and "activity and reactivity". The properties considered for category assignment are summarized in Table 6. The authors propose a testing strategy consisting of four steps: analysis of known information, hypothesis building, testing and assessment. 
Table 6 Overview of criteria for grouping used in the RIVM approach (Sellers et al. 2015)

\begin{tabular}{|c|c|c|}
\hline & & Key criteria \\
\hline \multirow[t]{2}{*}{ Phase I } & Chemical identity & $\begin{array}{l}\text { Composition } \\
\text { Crystalline structure } \\
\text { Surface characteristics (coating, functionalization, capping agents) } \\
\text { Impurities }\end{array}$ \\
\hline & Particle characteristics & $\begin{array}{l}\text { Particle size and range } \\
\text { Shape } \\
\text { Porosity } \\
\text { Surface area }\end{array}$ \\
\hline \multirow[t]{2}{*}{ Phase II } & Transport behaviour & $\begin{array}{l}\text { Solubility (dissolution, concentration) } \\
\text { Hamaker constant } \\
\text { Zeta potential } \\
\text { Dispersibility } \\
\text { Dustiness }\end{array}$ \\
\hline & Activity and reactivity & $\begin{array}{l}\text { Physical hazards (flammability, autoflammability, explosivity) } \\
\text { Reactivity } \\
\text { Photoreactivity }\end{array}$ \\
\hline
\end{tabular}

The Decision-making Framework for the grouping and testing of nanomaterials (DF4nano Grouping) developed by the European Centre for Ecotoxicology and Toxicology of Chemicals (ECETOC) (Arts et al. 2015) categorizes NMs into four groups, focusing on inhalation. To that end, intrinsic and extrinsic properties, use, release, exposure route, biopersistence, uptake, biodistribution and cellular and apical toxic effects are considered and evaluated in three tiers, assigning NMs into the following groups (Table 7): 1) soluble NMs, 2) biopersistent high aspect ratio NMs, 3) passive NMs and 4) active NMs. The first group comprises NMs whose solubility in water or medium is higher than $100 \mathrm{mg} / \mathrm{L}$. The possible toxicity of soluble NMs is not determined by their nano-nature per se, but mainly by their chemical composition and released ions. In contrast, the possible toxicity of "biopersistent high aspect ratio NMs" (group 2) is determined by their morphology and biopersistence in the organism. Criteria for assignment of NMs to "biopersistent high aspect ratio NMs" are a particle aspect ratio of 3:1 or higher, a length greater than $5 \mu \mathrm{m}$, a diameter less than $3 \mu \mathrm{m}$ and a solubility of less than $100 \mathrm{mg} / \mathrm{L}$, or a pulmonary half-life greater than 40 days. The third group comprises NMs with an absence of significant specific cellular effects and/or with no apical toxicity, which is indicated by the absence of effects in the alveolar macrophage assay, and the absence of significant surface reactivity, with a somewhat arbitrary limit of $10 \%$ of $\mathrm{Mn}_{2} \mathrm{O}_{3}$ reactivity as measured in the Ferric Reducing ability of Serum assay (FRAS) or in the cytochrome C assay. The hazard of these "passive NMs" is very low, even if inhalation of very high doses may induce adverse reactions. In contrast, "active NMs" (group 4) comprise NMs that elicit apical toxic effects even at low doses. This group encompasses all the NMs that could not be classified in the other groups. The first tier of testing, which aims to classify the NMs in the Group 1, considers three essential intrinsic material properties: water solubility, 
particle morphology (primary particle size, shape, aspect ratio and surface area) and chemical composition. The second tier of testing is used for classifying NMs into the groups 2 to 4 , assessing the following extrinsic properties: dissolution rate, surface reactivity, dispersibility and cellular effects as measured in vitro. A third tier of testing may be added if needed, and involves short-term in vivo inhalation studies (STIS). Three further parameters, use, release and route of exposure, are considered as qualifiers for waiving on basis of exposure scenarios and are used for justifying such waiving.

Table 7 Overview of criteria used in DF4nano grouping approach (Arts et al. 2015)

\begin{tabular}{|l|l|l|}
\hline & & Key criteria \\
\hline Tier I & $\begin{array}{l}\text { Group 1: } \\
\text { Soluble NMs }\end{array}$ & solubility (NM with a solubility (water) higher than $100 \mathrm{mg} / \mathrm{L}$ ) \\
\hline \multirow{2}{*}{ Tier II } & $\begin{array}{l}\text { Group 2: } \\
\text { Biopersistent HAR NMs }\end{array}$ & $\begin{array}{l}\text { - particle aspect ratio of 3:1 or higher } \\
\text { - a length greater than } 5 \mu \mathrm{m} \\
\text { - a diameter less than } 3 \mu \mathrm{m} \\
\text { - solubility of less than } 100 \mathrm{mg} / \mathrm{L} \\
\text { - pulmonary half-life greater than } 40 \text { days }\end{array}$ \\
\cline { 2 - 3 } & \multirow{2}{*}{ Group 3: Passive NMs } & $\begin{array}{l}\text { absence of significant specific cellular effects and/or no apical toxicity } \\
\text { (alveolar macrophage assay, Ferric Reducing ability of Serum assay - } \\
\text { FRAS, cytochrome C assay) }\end{array}$ \\
\cline { 2 - 3 } & Group 4: Active NMs & $\begin{array}{l}\text { NM that elicit apical toxic effects even at low doses (all NMs that could } \\
\text { not be classified in any other group) }\end{array}$ \\
\hline \multirow{2}{*}{ Tier III } & Group 3: Passive NMs & $\begin{array}{l}\text { (only if needed, to distinguish between passive/ active NMs) } \\
\text { based on short-term in vivo inhalation studies }\end{array}$ \\
\cline { 2 - 3 } & Group 4: Active NMs & \multicolumn{2}{|l}{} \\
\hline
\end{tabular}

The MARINA grouping and read-across approach is based on the MARINA RAS, as already described above (Oomen et al. 2015). It is based on the consideration that NMs can be grouped based on their chemical and physical identity (referred to as "What they are", including chemical composition, impurities, surface functionalization, size, shape and surface area), fundamental NM behaviour ("Where they go", including solubility, hydrophobicity, dispersibility and dustiness) and NM reactivity, i.e. the potential hazards ("What they do", including physical hazards, biological reactivity and photoreactivity), see Table 8. The MARINA risk assessment strategy (RAS) highlighted five possibilities for applying grouping and read-across within the RAS. In the first application ("to design a testing strategy whose results cover an entire group of NMs"), grouping is used for limiting the amount of testing, i.e. within a group of nanoforms, only a limited number of NMs need to be tested, and the results can then be considered representative for the entire group. For this purpose, NMs are grouped together according to their physico-chemical properties ("what they are") and their intended use. In the second, third, and fourth application, grouping is used for facilitating the risk assessment process. The second application uses the grouping approach "to indicate possibility for read-across early in the risk assessment". This applies, for example, to "soluble NMs", for which data on the corresponding ion(s) can be used. The third application uses grouping "to highlight 
information needs based on hazard". This applies e.g. to "NMs with a high aspect ratio". The fourth application is "grouping to highlight information needs based on exposure", which is useful for determining relevant exposure scenarios. The fifth application is "scientifically justified read-across for a specific endpoint or test", i.e. predicting one or more endpoints for a target NM by inter- or extrapolating data from one or several source NMs.

Table 8 Overview of criteria used in MARINA approach (Oomen et al. 2015)

\begin{tabular}{|l|l|}
\hline What they are & Key criteria \\
\hline Where they go & $\begin{array}{l}\text { Chemical and physical identity (chemical composition, impurities, } \\
\text { surface functionalization, size, shape, surface area) }\end{array}$ \\
\hline What they do & $\begin{array}{l}\text { Fundamental NM behaviour (solubility, hydrophobicity, dispersibility, } \\
\text { dustiness) }\end{array}$ \\
\hline
\end{tabular}

Hund-Rinke et al. (2018) developed a grouping concept for the ecotoxicity of NMs with similarities to the DF4nano Grouping approach. They considered the ecotoxicological effects on algae, daphnids and fish embryos and a set of intrinsic and extrinsic physico-chemical properties. These properties were assessed for a set of ion-releasing and non-ion releasing metal and metal oxide NMs. To account for the shading effect following the sorption of NMs to the algae, they also proposed to assess the sorption tendency of NMs. In order to achieve better regulatory compliance, the proposed ecotoxicity testing strategy is based on OECD test guidelines and statistical approaches were used to establish relationships between observed effects and intrinsic and extrinsic properties. The grouping concept has been applied for a different set of NMs.

In 2016 ECHA, JRC and RIVM published a joint document, which addresses important considerations regarding grouping and read-across for NMs. It aimed to provide scientifically justified approaches and guidance for read-across between nanoforms under REACH (ECHA, JRC, RIVM 2016). The joint document describes a tiered strategy to justify read-across between different nanoforms of the same substance. It consists of six steps: 1 ) identification of the nanoforms according to physico-chemical parameters; 2) initial grouping according to similarities in physico-chemical parameters, fundamental behaviour and reactivity; 3 ) identification of available data and data gaps; 4 ) identification of possible source NMs to fill in data gaps; 5) definition of a testing strategy to validate the hypothesis; and 6) performance of additional experiments, where needed. This joint paper was the basis for the ECHA Appendix R.6-1 for nanomaterials applicable to the guidance on QSAR and Grouping of Chemicals (ECHA 2017c), which describes a very similar approach. 


\section{Applicability of NM grouping frameworks for regulatory purposes}

The state of the art for NM grouping and categorization has been discussed at two OECD expert meetings, one on "Categorization of Manufactured Nanomaterials" (OECD 2016a) and one on "Grouping and Read-Across for the Hazard Assessment of Manufactured Nanomaterials" (OECD 2016b). The focus of the latter meeting was to provide initial input for a possible update of the OECD Guidance on Grouping of chemicals (OECD 2014). Although NMs are explicitly cited in this general OECD grouping guidance among specific types of chemical categories (chapter 6 ), to date only "initial considerations" are available in the dedicated section (section 6.9). A general conclusion at the OECD expert meeting confirmed the adequacy of applying grouping and read-across for data-gap filling for NMs and also concluded that section 6.9 needs to be revised, taking NM specificities into account (OECD 2016b). In September 2018 the OECD jointly with two European H2020 research projects, NanoReg2 and GRACIOUS, organized a scientific workshop on NM grouping to discuss recent progress. The workshop concluded that case studies are urgently needed to demonstrate the applicability of the various NM grouping concepts in practice. Indeed, although significant progress has been made to establish general and comprehensive frameworks for NM grouping, none of the approaches published has been formally validated and only very few of them have been demonstrated using a limited set of case studies due to lack of comprehensive data sets for validation. This results in uncertainty about their applicability.

In the following the regulatory applicability of each of the comprehensive NM grouping approaches under REACH is addressed, including a brief summary of whether they have been applied in case studies. This assessment is done only for the REACH regulation, which has been identified as the most important EU legislation for implementing NM grouping as it broadly covers nearly all chemicals (Mech et al 2018). Moreover, there is a specific guidance document on NM available (ECHA 2017c) to which the different grouping frameworks for NMs can be easily compared (Table 9).

Table 9 Comparison of the comprehensive NM grouping frameworks to the ECHA guidance

\begin{tabular}{|l|c|c|c|c|c|c|}
\hline & RCC 2013 & $\begin{array}{l}\text { RIVM } \\
\text { approach } \\
\text { (Sellers et } \\
\text { al. 2015) }\end{array}$ & $\begin{array}{l}\text { DF4nano } \\
\text { (Arts et } \\
\text { al. 2015) }\end{array}$ & $\begin{array}{l}\text { MARINA } \\
\text { (Oomen et } \\
\text { al. 2015) }\end{array}$ & $\begin{array}{l}\text { Hund- } \\
\text { Rinke et al. } \\
2018\end{array}$ & $\begin{array}{l}\text { ECHA guidance } \\
\text { (ECHA 2017c) }\end{array}$ \\
\hline $\begin{array}{l}\text { Different pieces of } \\
\text { information considered } \\
\text { in addition to physico- } \\
\text { chemical properties }\end{array}$ & $\mathrm{X}$ & $\mathrm{X}$ & $\mathrm{X}$ & $\mathrm{X}$ & $\mathrm{X}$ & $\mathrm{X}$ \\
\hline $\begin{array}{l}\text { Initial Grouping } \\
\text { Hypothesis required to } \\
\text { enter the framework }\end{array}$ & & & & & & $\mathrm{X}$ \\
\hline $\begin{array}{l}\text { Strategy described for } \\
\text { how to establish } \\
\text { Grouping Hypothesis }\end{array}$ & & & & $\mathrm{X}$ & $\mathrm{X}$ & \\
\hline Assign available data in & & & $\mathrm{X}$ & $\mathrm{X}$ & & \\
\hline
\end{tabular}




\begin{tabular}{|l|l|l|l|l|l|l|}
\hline $\begin{array}{l}\text { a data matrix/ Identify } \\
\text { data gaps }\end{array}$ & & & & & & \\
\hline $\begin{array}{l}\text { Strategy for how to fill } \\
\text { data gaps (i.e. specific } \\
\text { assays proposed) }\end{array}$ & & & $\mathrm{X}$ & & & \\
\hline $\begin{array}{l}\text { Clear threshold values to } \\
\text { assign NM in groups }\end{array}$ & & & $\mathrm{X}$ & & & \\
\hline Iterative Process & & & & & & \\
\hline
\end{tabular}

Going a little more into detail, we next assessed the specific information requirements. Each framework starts with assessing physico-chemical similarity based on sets of physico-chemical properties, which are overall very similar between the different frameworks and to a large extent also in line with the physico-chemical properties suggested in the ECHA guidance (see Table 10). Table 10 also includes the NANoREG approach for comparison reasons, even though this is not a specific grouping framework.

Table 10 Physico-chemical properties considered in the different grouping approaches

\begin{tabular}{|c|c|c|c|c|c|c|}
\hline & $\begin{array}{l}\text { RIVM } \\
\text { approach } \\
\text { (Sellers et } \\
\text { al. 2015) }\end{array}$ & $\begin{array}{l}\text { DF4nano } \\
\text { (Arts et al. } \\
\text { 2015) }\end{array}$ & $\begin{array}{l}\text { MARINA } \\
\text { (Oomen } \\
\text { et al. } \\
2015 \text { ) }\end{array}$ & $\begin{array}{l}\text { NANoREG } \\
\text { (Dekkers } \\
\text { et al. 2016) }\end{array}$ & $\begin{array}{l}\text { Hund- } \\
\text { Rinke et } \\
\text { al. } 2018\end{array}$ & $\begin{array}{l}\text { ECHA } \\
\text { guidance } \\
\text { (ECHA 2017c) }\end{array}$ \\
\hline Chemical composition & $x$ & $x$ & $x$ & $X$ & $x$ & $x$ \\
\hline Impurities & $x$ & $x$ & $x$ & $x$ & & $x$ \\
\hline Crystalline structure & $x$ & $x$ & $x$ & & $x$ & $x$ \\
\hline $\begin{array}{l}\text { Surface characteristics } \\
\text { (coating, } \\
\text { functionalization, } \\
\text { capping) }\end{array}$ & $x$ & $x$ & $x$ & $x$ & $x$ & $x$ \\
\hline Surface charge & $x$ & $x$ & $x$ & $x$ & & $x$ \\
\hline $\begin{array}{l}\text { Primary particle size } \\
\text { and range }\end{array}$ & $x$ & $x$ & $x$ & $x$ & $x$ & $x$ \\
\hline Shape/aspect ratio & $X$ & $x$ & $x$ & $x$ & $x$ & $x$ \\
\hline Rigidity & & $x$ & & $X$ & & \\
\hline Surface area/Porosity & $\mathrm{X}$ & $x$ & $x$ & $x$ & $x$ & $x$ \\
\hline Hydrophobicity & & $x$ & $x$ & & & $x$ \\
\hline Dustiness & $x$ & & $x$ & & & $x$ \\
\hline $\begin{array}{l}\text { Explosivity, } \\
\text { flammability }\end{array}$ & & & $x$ & & & \\
\hline Dispersibility & $x$ & & $x$ & & & $x$ \\
\hline $\begin{array}{l}\text { Aggregation/ } \\
\text { agglomeration }\end{array}$ & & & $x$ & $x$ & & $x$ \\
\hline Water solubility & $x$ & $x$ & $x$ & $x$ & & $x$ \\
\hline $\begin{array}{l}\text { Dissolution, } \\
\text { relevant media }\end{array}$ & $x$ & $x$ & $x$ & $x$ & & $x$ \\
\hline Acid dissociation & & & & $x$ & & \\
\hline Biopersistence & & $x$ & & $x$ & & $x$ \\
\hline Hamaker constant & $x$ & & & & & $(X)$ \\
\hline Dispersibility & $x$ & & $x$ & & & $x$ \\
\hline Dustiness & $x$ & & $x$ & & & $x$ \\
\hline Hydrophobicity & & $x$ & $x$ & & & $x$ \\
\hline $\begin{array}{l}\text { Explosivity, } \\
\text { flammability }\end{array}$ & & & $x$ & & & \\
\hline
\end{tabular}




\begin{tabular}{|l|l|l|l|l|l|l|}
\hline $\begin{array}{l}\text { Conduction band } \\
\text { energy/ } \\
\text { band gap }\end{array}$ & & & & $X$ & & \\
\hline
\end{tabular}

Toxicological endpoints and toxicological data considered in the RIVM, MARINA and NANoREG approaches comprise legal information requirements laid down in REACH (e.g. genotoxicity) and additional information obtained with other test methods than OECD test guidelines. Thus, these approaches are relevant for regulatory purposes. In contrast, both tier 2 and 3 of the DF4nano grouping framework uses only data from non-OECD test guidelines and are thus currently of limited applicability for regulatory purposes.

The RIVM approach describes two hypothetical case studies mainly to better illustrate the proposed grouping approach (Sellers et al. 2015). However, hypothetical cases cannot be considered validation, which was also noted by the authors.

The DF4nanoGrouping approach was applied in four case studies involving 25 different NMs and DQ12 quartz as a thoroughly studied bulk material (Arts et al. 2016). These case studies concern carbonaceous materials, metal oxides and metal sulphates, amorphous silica and organic pigments, including different particles, flakes, and fibres/tubes as well as un-coated and coated NMs. In each case, the tiered classification approach was applied and the materials were each assigned to a group. The classification was then compared to the results of short-term inhalation studies. Overall, the outcome of the grouping based on the proposed criteria matched the in vivo results, showing the accuracy and value of the approach.

A few more case studies are summarized in the OECD meeting report "Grouping and Read-Across for the Hazard Assessment of Manufactured Nanomaterials" (OECD 2016b).

The largest uncertainty for these approaches remains the fact that they have not, or have only to a limited extent, been applied in specific grouping case studies, except for the DF4nanoGrouping approach. Thus, the shortage of comprehensive data sets for specific grouping case studies clearly is one of the biggest bottlenecks when putting NM grouping into practice.

Finally, although the ECHA guidance (ECHA 2017c) presents the most comprehensive approach, which for the first time describes the process of NM grouping as iterative in a clearly structured manner, it is simply guidance and lacks details and clarity in some aspects. For instance, the guidance states that a specific grouping hypothesis is needed to enter the framework but does not describe how such a grouping hypothesis should be established, which is actually linked to the question on how to establish similarity and how to link physico-chemical properties to adverse effects. On the other hand, this guidance is a special case, as under REACH it is up to the REACH registrants to define 
their grouping principles and groups and to be able to defend them. Thus, the ECHA guidance is not prescriptive with respect to this.

It becomes obvious that improving existing NM grouping approaches is urgently needed for applicability in real practice. A few interesting concepts have already been published that could prove useful for improving the existing approaches as described in the next section.

\section{Interesting concepts to be considered in further development of NM grouping approaches}

Several conceptual approaches have been published that can provide useful input for further developing or extending NM grouping aproaches. In the following we briefly summarize four useful conceptual approaches (see Table 11) .

Table 11 Conceptual approaches useful in further development of grouping approaches for NMs

\begin{tabular}{|c|c|c|c|c|}
\hline Approach & Aim & Key criteria & Opportunities & Limitations \\
\hline $\begin{array}{l}\text { Toxicological } \\
\text { Prioritization } \\
\text { Index (ToxPi }{ }^{\mathrm{TM}} \text { ) } \\
\text { (Reif et al. 2010) }\end{array}$ & $\begin{array}{l}\text { Prioritization and } \\
\text { Hazard Ranking of } \\
\text { endocrine disruptors }\end{array}$ & $\begin{array}{l}\text { Weighted } \\
\text { combination of } \\
\text { data from high- } \\
\text { throughput } \\
\text { screening, Omics, } \\
\text { Physico-chemical } \\
\text { characterization, } \\
\text { Exposure }\end{array}$ & $\begin{array}{l}\text { Strategy to integrate } \\
\text { and analyse different } \\
\text { type of data, ranking }\end{array}$ & $\begin{array}{l}\text { High amount of } \\
\text { data needed }\end{array}$ \\
\hline $\begin{array}{l}\text { Nel et al. (Nel et } \\
\text { al. 2013) }\end{array}$ & $\begin{array}{l}\text { Predictive toxicology } \\
\text { approach }\end{array}$ & $\begin{array}{l}\text { High-throughput } \\
\text { screening, } \\
\text { Structure-activity } \\
\text { relationship }\end{array}$ & $\begin{array}{l}\text { Establish structure } \\
\text { activity } \\
\text { relationship(s) }\end{array}$ & $\begin{array}{l}\text { Limited to specific } \\
\text { types of materials } \\
\text { (chemical } \\
\text { composition) }\end{array}$ \\
\hline $\begin{array}{l}\text { Lynch et al. } \\
\text { (Lynch et al. } \\
2014 \text { ) }\end{array}$ & $\begin{array}{l}\text { Categorization based } \\
\text { on Mode of Action } \\
\text { using different input } \\
\text { parameters and } \\
\text { Principal Component } \\
\text { Analysis }\end{array}$ & $\begin{array}{l}\text { Modes of action } \\
\text { 1) Dissolution, } \\
\text { 2) Surface effects, } \\
\text { 3) Structure effects } \\
\text { 4) Trojan horse } \\
\text { effect }\end{array}$ & $\begin{array}{l}\text { Strategy to combine } \\
\text { descriptors } \\
\text { describe MoA }\end{array}$ & $\begin{array}{l}\text { Plausibility } \\
\text { no } \\
\text { mechanism } \\
\text { proof } \\
\text { combination } \\
\text { descriptors of } \\
\text { truly linked to } \\
\text { toxicity }\end{array}$ \\
\hline $\begin{array}{l}\text { Landsiedel } \\
\text { (Landsiedel 2016) }\end{array}$ & $\begin{array}{lll}\text { Use grouping } & \text { to } \\
\text { identify NMs } & \text { of } \\
\text { concerns } & & \end{array}$ & $\begin{array}{l}\text { Source-to-adverse- } \\
\text { outcome pathway } \\
\text { (SAOP) }\end{array}$ & $\begin{array}{l}\text { Grouping is applied in } \\
\text { different steps of NM } \\
\text { life cycle }\end{array}$ & $\begin{array}{l}\text { Not always possible } \\
\text { and efficient }\end{array}$ \\
\hline
\end{tabular}

The Toxicological Prioritization Index (ToxPi ${ }^{\mathrm{TM}}$ ) is a tool developed by the U.S. Environmental Protection Agency (EPA, see https://www.epa.gov/) within the ToxCast program for ranking and prioritization of chemicals (Reif et al. 2010). It aims to integrate different types of information on chemicals, introducing a dimensionless index score, the so-called Toxicological Priority Index (ToxPi), which is calculated as a weighted combination of all data sources, including data obtained from high- 
throughput screening (HTS), omics technologies, physico-chemical characterization data and exposure data. The authors have also developed an interactive ToxPi Graphical User Interface application, which supports the sharing of data across different platforms (Reif et al. 2013).

Nel et al. have developed a two-phase approach for the testing of NM toxicity (Nel et al. 2013). In the first phase, data from HTS in-vitro testing is used to determine the most relevant properties of the NMs that are responsible for the onset of a specific outcome. This approach identifies four main research needs: the generation of libraries with high data content to overcome the lack of standard or reference materials, the use of HTS for a quantitative assessment of dose- and time-response relationships, the determination of underlying mechanistic pathways and the development of a data analysis framework. In the second phase of the approach, the results are confirmed by targeted invivo experiments and structure-activity relationships (SARs) are established. The authors considered two case studies: metal oxide NMs and multi-walled carbon nanotubes. A regression model was used to develop a SAR for metal oxide NMs. Four physico-chemical parameters, which are essential for describing the in vitro induction of oxidative stress toxicity were determined: atomization energy, periodic table number of the metal, nanoparticle volume and primary particle size.

Lynch et al. proposed that NM toxicity can be explained by four different MoAs, 1) NM dissolution, 2) NM surface effects, 3) NM structure effects and 4) a Trojan horse effect (Lynch et al. 2014a). The four MoAs were justified by considering three principal components (based on intrinsic properties, extrinsic properties and composition aspects) and several descriptors, which can influence the principal components. Examples of intrinsic properties include NM structure, shape, porosity, structural configuration and bandgap. The extrinsic properties depend on the NM surface area and its interaction with the NM's biological environment. Examples include surface interactions and transformations of the surface. The composition aspects include properties such as inherent toxicity, charge, hydrophobicity and coating. This strategy takes into consideration that while a specific MoA is determined by a specific property, it can also be influenced by other factors. As an example the authors use the dissolution of a NM, which is mainly determined by its chemical composition (an intrinsic property) but also modulated by extrinsic properties, such as the presence of strongly binding ligands on the surface, and by other intrinsic properties such as structural configuration.

Landsiedel has published an opinion paper outlining different possibilities for NM grouping, following a so-called source-to-adverse-outcome pathway (SAOP) and emphasizing that NM grouping should not be restricted to the determination of nanostructure-activity relationships (Landsiedel 2016). The author suggests a multi-perspective grouping approach according to (i) production, use and release of NMs over the entire lifecycle; (ii) physico-chemical properties of NMs, which may change during 
the life cycle; (iii) uptake, biodistribution and biopersistence of NMs in an organism and (iv) early, apical biological effects of NMs. A specific NM can belong to several different categories or to none.

\section{NM Grouping: The NanoReg2 contribution}

The specific aim of the NanoReg2 project was to establish and verify NM grouping strategies, which comply with regulatory needs most importantly for REACH, in order to support a framework that can be applied within NM risk assessment. At the same time, the approach should allow to support Safe by Design (SbD) concepts. The NanoReg2 team identified the MARINA grouping strategy (Oomen et al. 2015) as the most suitable starting point, since it is best in line with the ECHA guidance (ECHA 2017c) (Tables 9 and 10). Moreover, the MARINA approach is the most general one, applicable both for regulatory purposes and for supporting SbD by taking into account different stages of the NM's life cycle, which was important for NanoReg2. Importantly, within NanoReg2, the MARINA grouping strategy was further modified by a) extending the NM physico-chemical characterization (according to the NANoREG physico-chemical characterization scheme, see NANoREG deliverable D2.5, www.nanoreg.eu), b) focusing further on transformations of NMs in biological media (in particular by taking into account specific interactions between NMs and proteins), c) integrating ecotoxicity and d) integrating computational tools at different stages. The adaptations are explained in the following in more detail. The resulting NanoReg2 grouping strategy is summarized in Figure 1. 


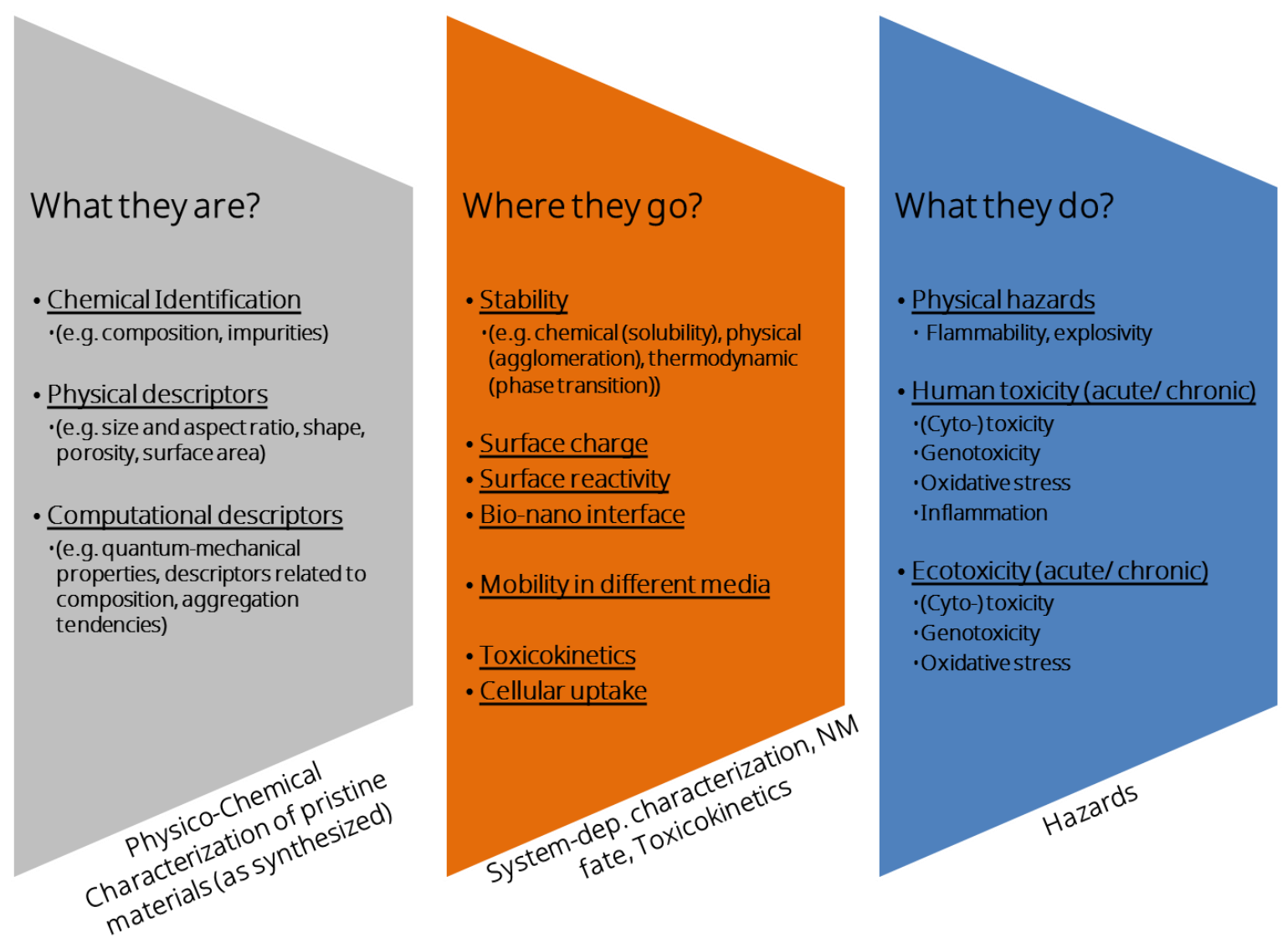

Figure 1: Scheme summarizing the most important parts of the NanoReg2 NM grouping approach

Building on the MARINA approach, NanoReg2 suggests starting from the analysis of the three pillars, "What they are", Where they go" and "What they do" for characterizing NM intrinsic, extrinsic and hazard properties respectively.

\section{What they are}

The "What they are" pillar of the original MARINA approach was significantly extended in the NanoReg2 project in two ways: i) by more precisely specifying the measured physico-chemical properties in order to describe a NM's physico-chemical identity and ii) by including additional calculated descriptors that may be useful for grouping. Thus, NanoReg2 took into account the further knowledge on NM physico-chemical characterization developed in the EU FP7 project NANoREG. The proposed properties cover the minimum physico-chemical information needed to describe the intrinsic characteristics of NMs. To that end, the NanoReg2 approach relies on the regulatory definition of a "nanomaterial" as recommended by the EC (EU 2011/696). The NanoReg2 approach starts by collecting the following data for the characterization of the pristine materials (i.e. as synthesized): primary particle size (distribution), shape, surface area, chemical composition, purity, impurities, atomic structure, surface chemistry/coating, structural complexity, zeta potential, stability, solubility and compartment specific solubility. Furthermore, dustiness is important in the context of inhalation toxicity, where it can be used as measured according to the EN15051 standard 
or as modelled (e.g. Levin et al. 2014; Koivisto et al. 2015; Fonseca et al. 2018). However, dustiness can also be used for the assessment of physical hazards such as for explosivity. Moreover, physical parameters such as smouldering temperatures, Self Ignition temperatures, Minimum Ignition temperatures, Minimum Ignition Energy, Lower Explosion Limits, Maximum explosion pressure, Explosion severity should be considered for flammability and explosivity, as new SOPs (standard operating procedures) for NMs have recently been proposed and approved at the CEN nanotechnology level (CEN/TS 17274:2018, Bouillard et al. 2018).

Importantly, the NanoReg2 approach also suggests to include theoretical, i.e. calculated descriptors for NM characterization in addition to the measured ones. These comprise easily computable and interpretable parameters calculated for metals, metal cations and nanoclusters that have been widely used in a number of nano-QSAR models developed for inorganic nanoparticles, e.g. standard enthalpy of formation of gaseous metal ions, ionization potential energy, highest occupied molecular orbital (HOMO) and lowest unoccupied molecular orbital (LUMO) energies, band gap energy, liquid drop model descriptors and periodic table-based descriptors (Puzyn et al. 2011, Kar et al. 2014, Sizochenko et al. 2014, Sizochenko et al. 2015, Mikolajczyk et al. 2015). In particular, HOMO and LUMO values are quantum-mechanical properties that strongly depend on the structure of a nanoform. The dominating structural parameter can be either its size, or its crystalline phase (for instance anatase or rutile), or other properties (Gajewicz et al. 2011).

\section{Where they go}

This pillar includes all parameters suggested by the MARINA approach. It has been extended by the characterization of the bio-nano interface by Isothermal Titration Calorimetry (ITC), as described in more detail below. Regarding the MARINA parameters, solubility and dissolution are considered particularly important in this context. The solubility of substances and rates of dissolution vary with media compositions and other extrinsic parameters such as presence of $\mathrm{pH}$-buffering, atmosphere composition, temperature, material concentration etc. (e.g. Utembe et al. 2015; Bove et al. 2017; Koltermann-Jülli et al. 2018). Different parts of the particle (e.g. the coating and the core) may also have different solubilities and dissolution rates in which a coating may function as a protective capping on the NM. Characterisation of NMs at different points of their life cycle and in different systems is important, as some properties of the NMs may depend on the system and on the stage of the life cycle (system-dependent properties), thereby also changing the group relevant to the NM. Apart from solubility and dissolution, the NanoReg2 approach also emphasizes inclusion of zetapotential, NM stability, and in particular NM surface reactivity, which could belong to "where they go" as well as to "what they do". Surface reactivity can be assessed by different assays even if in the absence of validation their reliability remains unknown. NanoReg2 focused explicitly on the ability of 
NMs to produce reactive oxygen species (ROS) in acellular assays. We will address this issue in the following "what they do" section, as the ROS production is related to the induction of oxidative stress in cellular assays and thus to toxicity. Another unique feature of the NanoReg2 approach is the characterization of the bio-nano Interface by using Isothermal Titration Calorimetry (ITC), which measures the interactions between the NM surface and selected model proteins that are representative of the protein corona of that NM. The issue related to the interaction of NM with proteins was also addressed in NANoREG by an in-depth study of protein interaction with ZnO NMs using in vitro toxicity methods (Da Silva et al., 2019a; 2019b), but not included in the NANoREG grouping approach. The tendency of NM to interact with biomolecules is considered to be the result of their need to reduce their surface energy (Lynch et al. 2014b, Walczyk et al. 2010). The thermodynamic profile/signature (i.e., changes in enthalpy, entropy, free energy) measured by ITC provides clues to understanding these binding driving forces/factors and could be correlated with cellular uptake ((Fleischer and Payne 2014; Mosquera et al. 2018, Zhu et al. 2012). Based on ITC measurements NMs can be categorized in three categories.

Category I: $\Delta H<0, \Delta S<0$ : Bindings with favourable enthalpy, $\Delta H$, and unfavourable entropic changes, $\Delta S$. This thermodynamic signature indicates a predominant enthalpic binding, driven by van der Waals and/or electrostatic forces.

Category II: $\Delta H>0, \Delta S>0$ : Bindings occurring with low unfavourable enthalpy, $\Delta H$, and high favourable entropic changes, $\Delta S$. This thermodynamic profile is specific for an interaction dominated by hydrophobic forces.

Category III: $\Delta H<0, \Delta S>0$ : Bindings with both favourable enthalpy, $\Delta H$, and favourable entropy, $\Delta S$, were also detected, which show that those bindings were dominated by hydrophobic forces, but characterized by slightly electrostatic forces, suggesting that the inorganic particles establish a number of bonds with the proteins.

Thus, the changes of enthalpy $(\Delta \mathrm{H})$ and entropy $(\Delta \mathrm{S})$ of binding are being considered as the driving factors for protein-NM binding, their contributions to the free energy of binding $(\Delta G)$ being closely related. The identification of specific energy parameters driving the binding interactions at the bionano interface, i.e. describing the interactions between a NM and several selected relevant proteins, is an important step within the NanoReg2 grouping approach. Thermodynamic data have been used for the analysis of some case studies taking into account the effect of different variable e.g. NM type, particle size, crystalline structure, hydrophobicity on the binding characteristics. It was shown that within individual groups of NMs, the thermodynamic profile is depending on different physicochemical features and compositional variables. At the same time, these data allow for an analysis of the correlation between thermodynamic parameters at the bio-nano interface and the 
outcome of toxicological results (Tanasescu et al 2014). This provides a novel aspect for NM grouping, contributing to the effort for validation of some previously proposed grouping criteria and supporting the selection and prioritization of NMs for further testing.

\section{What they do}

NanoReg2 considers all endpoints related to physical hazards and to human health effects of the MARINA approach and extends them in two ways, firstly by providing novel SOPs specifying precisely how the physical hazards can be assessed and secondly by substantially extending the MARINA approach with respect to environmental hazards. Thus, the NanoReg2 is the first truly comprehensive approach that covers both human and environmental hazards. NanoReg2 suggests establishing groups of NMs by primarily considering data obtained in in vitro studies that followed OECD test guidelines (TGs), where available. However, NanoReg2 also considers data obtained by following SOPs established in other EU projects, in particular, SOPs from NanoGenoTox, NANoREG and MARINA were considered relevant and sufficiently reliable. In addition, some SOPs were developed within the NanoReg2 project, such as the SOPs for characterizing physical hazards (CEN/TS 17274:2018). Physical hazards were already mentioned in the MARINA approach but clarity with respect to the underlying test methods were lacking.

When developing case studies for the NanoReg2 approach, available data was used as much as possible, thus limiting experimental efforts. Taking into account the availability of data in the NanoReg2 database, consisting of data from NANoREG, MARINA, Nanotest, NanoGenotox and ENPRA projects, the developed approach proposes to assess the hazard of NMs by using in vitro assays considering Cytotoxicity/Cell viability/Cell proliferation, Genotoxicity and Oxidative stress. Since currently no guidance is available for NMs on the usefulness and reliability of the various assays, NanoReg2 suggests and considers a selection of assays for each endpoint.

Cytotoxicity/Cell viability/Cell proliferation is suggested to be assessed using the following assays: Alamar Blue (AB), MTS assay, neutral red (NR) uptake, impedance measurement, Colony Forming Efficacy (CFE). SOPs exist for each of these assays and are available on NANoREG website (see deliverable D5.7, www.nanoreg.eu) and relevant information could be retrieved from the NanoReg2 database (https://search.data.enanomapper.net/about nanoreg2.html).

Genotoxicity is suggested to be assessed using the following assays: comet assay (with/without 8oxoguanine DNA glycosylase (Fpg) that detects oxidised or ring-opened purines resulting from breakdown, oxidised or alkylated purines, among them 7,8-dihydro-8-oxoguanine (8-oxoguanine) and 8-oxoadenine DNA modifications (Boiteux et al. 1992, Dusinska et al. 1996)), mammalian gene mutation assays, and the micronucleus assay. SOPs for each of those assays were established within the NANoREG project and are available online (see deliverable D5.7, www.nanoreg.eu). 
Oxidative stress may be addressed by using various acellular assays that assess the potential of the NM to produce ROS, such as electron paramagnetic resonance (EPR) or the acellular dichlorofluorescein assay ( $\mathrm{DCFH}_{2}$-DA). In addition, various cell-based assays can be included that also assess ROS formation but in a biological environment, employing dyes such DCFH $_{2}$-DA or dihydroethidium (DHE). Furthermore, we suggest to measure DNA damage by using the Comet-Ffg assay and protein damage by assessing protein oxidative carbonylation. It should be noted that currently, very few and tentative SOPs exist for assessing oxidative stress (see for example NANoREGdeliverable D5.7, www.nanoreg.eu).

Ecotoxicity was not considered in detail within the MARINA approach but elaborated in the NanoReg2 grouping approach. Ecotoxicity is assessed in vitro using mussel hemocyte cells and fish cell lines with assays such as the MTT assay, Alamar Blue assay, neutral red uptake or plasma membrane integrity assessment with the CFDA-AM staining method. In vivo approaches utilizing the freshwater microalgae Pseudokirchneriella subcapitata growth inhibition test (OECD TG 201) and the Daphnia magna acute immobilization test (OECD TG 202) are also used to assess ecotoxicity of NMs, although Hund-Rinke et al. (2016) indicate that these OECD TGs may need supporting guidance before they can be applied to NMs.

\section{Challenges faced during NM Grouping Case Studies}

The NanoReg2 NM grouping approach was applied in NM grouping case studies. Here we highlight the general strategy applied to establish the case studies and specifically the most important challenges. First of all, it was important to establish case studies demonstrating variations both within and between chemical substances. NanoReg2 therefore selected several material classes each with several nanoforms, based on industrial relevance and data availability. Then, an exploratory approach was followed, aiming at linking physico-chemical properties (intrinsic or extrinsic; measured or calculated) to specific hazard profiles, based on cellular responses connected to toxicological endpoints specifically covered by the REACH regulation. The overarching goal was to provide guidance on how to establish a group of NMs, especially in the absence of a specific starting hypothesis. During establishment of these case studies we faced three main challenges: a) limited availability of data, b) non-harmonized experimental methods for NM testing and c) serious concerns regarding the data quality, as already reported by others as a crucial issue (e.g. OECD 2016b). Below we briefly describe these challenges and provide some recommendations on how to address them.

a) To meet the first challenge, i.e. to face the scarcity of data, all original data derived from publicly funded research projects should be stored in publicly accessible databases, in line with the EU US 
Roadmap Nanoinformatics (EU US Roadmap Nanoinformatics 2030, 2018),. Enhanced data availability would help to overcome the fact that scientific publications and project reports generally do not contain all the details required for the re-use of the data for e.g. meta-analysis, grouping or other purposes. In ideal nano-databases, all experimental parameters should be reported as metadata alongside with the original datasets in order to enhance the usefulness of the datasets, to allow data conversion and re-analysis (e.g. for harmonization of dose units $\mu \mathrm{g} / \mathrm{mL}$ or $\mu \mathrm{g} / \mathrm{cm}^{2}$ ) and to address concerns regarding data quality. The eNanoMapper model (Jeliazkova et al. 2015) can serve as a best-practice example of building such data collections and is currently being implemented in several EU projects, including NanoReg2. Ideally, such a database will be robust enough to contain most forms of toxicological and physico-chemical data and it would appear that the ontologies developed so far in eNanoMapper make it one of the best candidates to become a universal repository. However, a few hurdles remain before its use can be enforced for future EU funded projects; this includes the incorporation of different dataset specific annotations, such as omics data, and environmental exposure data. Currently, the EU H2O2O nanoCommons project is working on a data management plan towards the development of standard ontologies and a repository of protocols and associated metadata templates. Full implementation of these ontologies and metadata would make eNanoMapper the logical choice to become the standard repository for NMs related data. Further standardisation of this process, together with the implementation of FAIR (findable, accessible, interoperable and reusable) principles on data management through other projects, such as EU H2O20 ongoing Gov4Nano, NANORIGO and RiskGone projects, could see the development of mandatory reporting regimes put in place for past and future EU-funded projects and data generated elsewhere. The collection of data induces the need to harmonize the data storage format for data warehousing, for example by using the NANoREG templates for the eNanoMapper database or the OECD Harmonised Templates (OHTs, http://www.oecd.org/ehs/templates/). Some of these OHTs reflect nano-specific endpoints, and since the OECD TGs are being reviewed with regard to their applicability to NMs, more of the templates could also be adapted to collect detailed information on NMs. Some EU H2020 projects (such as nanoCommons, NanoinformaTIX and NanoSolvelT) are currently working on extending and interlinking existing databases to make them more suitable for modelling and risk assessment purposes. In addition, the current scarcity of reliable data could be addressed by using validated high-throughput (screening) approaches (see for instance NANoREG deliverable D5.7, www.nanoreg.eu) and predictive toxicogenomics (Nymark et al. 2018a; Nymark et al. 2018b; Kohonen et al. 2017). High throughput screening platforms (including high-content analysis and omics technologies) employed in tiered workflows and accompanied by computational, automated data evaluation appear to be important tools to address NM complexity (Damoiseaux et al 2011, Nel et al. 2013, Collins et al. 2017, EU US Roadmap Nanoinformatics 2030, 2018). Several 
intelligent data-handling methods have recently been described for chemical data, including approaches such as the ToxPi tool described above (Reif et al. 2013) for scoring and integrating diverse data. Furthermore, the nanosafety community can learn from the way similar issues of data scarcity are currently addressed in the assessment of chemicals in general (e.g. Judson et al. 2013). Moreover, high-throughput screening and predictive toxicogenomics offer great opportunities to establish NM grouping based on MoAs and by knowledge of adverse outcome pathways (AOPs) or to substantiate a previously formulated grouping hypothesis (Vietti et al. 2016). Labib et al. (2016), for instance, used literature data to identify key biological events associated to lung fibrosis after MWCNTs exposure and proposed an AOP. They then used transcriptomics data to calculate the benchmark doses (BMDs) for the perturbed biological pathways identified in the AOP and suggest exploiting such BMDs to identify potentially harmful NMs, even when data on conventional toxicological endpoints are missing. The AOP approach may as well inform whether differences exist in the toxicodynamic properties of NMs compared to similar chemicals. Gerloff et al. (2017) have recently provided an example based on studies in which liver toxicity as a result of NM and chemical exposure was monitored. The model was able to link the molecular initiating event (MIE) with the adverse outcome by following a sequential path of connected Key Events at different levels of biological organization. It should be noted that the investigations of the system-dependent changes at the bio-nano interface can also contribute to the development of MoAs and AOPs for NMs as these data may inform on possible MIEs. Within NanoReg2 we addressed this issue by evaluating thermodynamic parameters driving the binding interaction between NMs and selected proteins using ITC. This knowledge may be used to inform about a MIE for some NMs. The concepts of MoA and AOP are as well investigated in projects such as NanoToxClass, SmartNanoTox, PATROLS and GRACIOUS.

b) For the second challenge, i.e. to establish and share standardized procedures for testing NMs strong and combined efforts are needed, ideally by international organisations such as OECD. The OECD has started the process of updating its TGs: TGs 412 and 413 (Subacute Inhalation Toxicity: 28Day Study / 90-day Study) were amended in 2018, and a new TG 318 (Dispersion Stability of Nanomaterials in Simulated Environmental Media) was adopted in 2017. However, development or adaptation of OECD test guidelines and guidance documents takes time. Rasmussen et al. 2019 give an overview of ongoing efforts within the OECD concerning test guidelines and guidance documents addressing nano-specific issues. Importantly, several EU projects such as Gov4Nano, RiskGone and NanoRIGO also address the adaptation of OECD TGs to meet the needs of NMs. At the same time some EU projects such as PATROLS focus on delivering new tools for NM hazard assessment by developing new and/or enhanced in vitro models, which better reflect real physiology. An important first step toward having agreed methods is the publication of detailed best-practice SOPs that are 
ideally verified in round robin tests, as noted elsewhere (Haase and Lynch 2018, Oomen et al. 2018). As already stated, we consider the NanoGenoTox, NANoREG and MARINA SOPs as good starting points to be used consistently in EU projects, when validated TGs are not available. The main recommendation is, however, to store the data together with the SOPs in databases in order to facilitate the comparison of the results and the interpretation of any contradictory data.

c.) The third challenge, i.e. assessing the completeness and the quality of existing NM datasets, is at the current stage a non-trivial task (Marchese Robinson et al. 2016). Efforts to provide methods and guidance for data quality assessment are ongoing in other projects (see e.g. caLIBRAte deliverable D5.3 on http://www.nanocalibrate.eu/home). The efforts described above to solve data availability and to provide harmonized testing procedures are also crucial for obtaining the reliable data needed for establishing, improving and verifying both NM grouping approaches and computational approaches in general. These recommendations will both facilitate NM grouping and subsequent risk assessment and support other purposes such as SbD.

The analysis made in this review indicates that most concepts for NM grouping address several different aspects of the NM's life cycle. All concepts take into account, to different extents, NM physico-chemical properties, NM interactions with its surroundings, specific types of use and exposure, NM uptake and toxicokinetics, as well as possible early and apical biological effects. None of the evaluated NM grouping concepts fully considers all of these aspects, and importantly, NM grouping may not need to address all of them. In order to achieve a better consensus on the grouping framework, new strategies are required for establishing predictable relationships between sets of physico-chemical properties of NMs and their (eco)toxicological effects. To that end, computational approaches can be very useful to prioritize the many NM properties, as already quite well established for chemicals in general (Patlewicz et al. 2017). NanoReg2 therefore suggests using computational approaches at the different tiers of NM grouping. This concept is also explained and emphasized in detail in the recently released EU US Nanoinformatics Roadmap 2030 (EU US Roadmap Nanoinformatics 2030, 2018).

Furthermore, we suggest functionality-driven and exposure-based grouping concepts. NMs readily undergo pronounced interactions with their surroundings, which may alter the NMs significantly at the different stages of their life cycle. Thus, the grouping of NMs can most likely not be established reliably without a specific use context to indicate possible routes of exposure and thus provide a means of targeted hazard assessment within the specific case of grouping.

Finally, we stress an urgent need for comprehensive high-quality date sets to complete more specific NM grouping case studies in order to identify possible gaps or inconsistencies in currently proposed NM grouping approaches. This in turn will eventually lead to more clarity on how to reliably apply 
NM grouping in a regulatory context. An important step towards this aim was the adoption of the amended REACH annexes (EU 2018/1881), providing clarity on the REACH registration information requirements for NMs. This regulatory development may increase the number of NMs registered under REACH and the associated datasets. Since this enhances the utility of the proposed grouping and read-across methods, further development of NM grouping concepts and approaches is likely. Importantly, this is also likely to increase the number of available grouping case studies specific to NMs.

\section{Conclusions and Outlook}

As described in detail in our paper, grouping and read-across can be considered appropriate tools for filling in data gaps in the hazard assessment of chemicals in general and also for NMs. Different European chemical legislation allow for grouping and read-across as alternative methods to provide data. Concerning NM grouping, currently the most advanced regulatory framework exists within REACH (EC 1907/2006). Within the last decade, significant progress has been made and several comprehensive science-based frameworks for NM grouping have been published. The general approach defined in the joint ECHA, JRC and RIVM document (ECHA, JRC, RIVM 2016), which is also the basis for the ECHA guidance (ECHA 2017c) can be regarded as the most comprehensive compilation of regulatory requirements, in particular as it emphasizes an iterative process to establish a group of nanoforms within one substance registration. However, it currently lacks guidance on how to establish grouping hypotheses, and furthermore it lacks clarity with respect to the underlying testing strategies to fill data gaps and does not indicate specific thresholds to facilitate decision-making, which is prerequisite for any grouping. Under REACH it is up to the registrants to define their grouping principles and groups and defend it, and thus the guidance is not prescriptive in detail.

The MARINA NM grouping approach (Oomen et al. 2015) is also highly useful, as it is a very broad approach, which can be applied for regulatory as well as for non-regulatory (e.g. SbD) purposes. Furthermore, different ways to implement and apply grouping and read-across during risk assessment are highlighted in this approach.

Moreover, the NanoReg2 approach provides more detailed information on how to identify a nanoform and it suggests several improvements such as the use of theoretical descriptors. In conclusion, a series of recommendations can be made based on the insights gained from the NanoReg2 grouping case studies: 
1) To include more specifically system-dependent properties such as the thermodynamic data suggested by NanoReg2 and exposure-based grouping concepts in the grouping framework;

2) To apply an exploratory strategy (such as the one indicated by NanoReg2) to enter the framework in cases where an initial hypotheses may not be obvious to establish;

3) To verify the quality and robustness of the proposed grouping framework by several case studies using different material types. The EU H2020 project GRACIOUS currently performs a significant number of case studies using well-characterized materials. For better comparison, especially in the absence of harmonized test methods benchmark materials should always be included. NanoReg2 strongly recommends using NMs from the JRC repository, as these have been intensely studied, resulting in vast knowledge on their properties and known effects and they may therefore be suitable in cases where specific materials, which can serve as particulate positive and negative controls for specific assays, are missing.

4) To integrate results from assays based on different principles by developing and harmonizing scaling, scoring and integration methods. Within NanoReg2, several assays were suggested to address specific toxicological endpoints and preliminary scoring methods to better compare and integrate the assays were proposed and applied on the case studies.

5) To develop new computational strategies to reliably find relationships between NM properties and (eco)toxicological effects. Computational approaches are useful at different stages of NM grouping, for example to develop or support initial grouping hypotheses. Different techniques can be used. These include read-across, unsupervised and supervised machine learning methods as well as various QSAR approaches. The different computational approaches, which can be applied are reviewed in the final report of the NanoComput project, where the predominant role of Quantitative StructureProperty Relationship (QSPR) and Quantitative Structure-Activity Relationship (QSAR) models is stressed (Worth et al. 2017). Future developments are intended to include such efforts as mechanism-aware QSARs and omics-based QSARs. Projects such as SmartNanoTox, NanolnformaTIX, NanoSolvelT and nanoCommons guide the development of such in silico approaches. In addition, future developments in computational nanotoxicology have been described in the EU US Roadmap Nanoinformatics 2030.

\section{Acknowledgement/ Funding}

This work was performed within the EU project NanoReg2, funded by the Horizon 2020 Framework Programme of the European Union under Grant Agreement Number 646221. 


\section{Abbreviations}

NM: NanoMaterial; REACH: Registration, Evaluation, Authorisation and restriction of CHemicals; QSAR: quantitative structure-activity relationship; ITS: Intelligent Testing Strategy; RAS (MARINA): Risk Assessment Strategy; ROS: reactive Oxygen Species; CMAR: Carcinogenic, Mutagenic, Asthmagenic, Reprotoxic; OEL: occupational exposure limit; CLP: Classification Labelling and Packaging; RL: risk Level; HB: Hazard Bands; HTS: High-Throughput Screening; SAR: structure-activity relationship; SbD: Safe by Design; ITC: Isothermal Titration Calorimetry; TG: Testing Guideline; SOP: Standard Operating Procedure; MoA: Mode of Action; AOP: Adverse Outcome Pathway; OHT: OECD Harmonized Templates

\section{References}

Arts JHE, Hadi M, Keene AM, Kreiling R, Lyon D, Maier M, Michel K, Petry T, Sauer UG, Warheit D, Wiench $\mathrm{K}$ and Landsiedel R. 'A critical appraisal of existing concepts for the grouping of nanomaterials' Regulatory Toxicology and Pharmacology 70(2): 492-506. 2014

Arts JHE, Hadi M, Irfan MA, Keene AM, Kreiling R, Lyon D, Maier M, Michel K, Petry T, Sauer UG, Warheit $\mathrm{D}$, Wiench $\mathrm{K}$, Wohlleben $\mathrm{W}$ and Landsiedel R. 'A decision-making framework for the grouping and testing of nanomaterials (DF4nanoGrouping)', Regulatory Toxicology and Pharmacology, 71: S1-S27. 2015

Arts JHE, Irfan MA, Keene AM, Kreiling R, Lyon D, Maier M, Michel K, Neubauer N, Petry T, Sauer UG, Warheit D, Wiench K, Wohlleben W and Landsiedel R. 'Case studies putting the decisionmaking framework for the grouping and testing of nanomaterials (DF4nanoGrouping) into practice', Regulatory Toxicology and Pharmacology, 76: 234-61. 2016

Aschberger K, Asturiol D, Lamon L, Richarz A, Gerloff K, Worth A. Grouping of multi-walled carbon nanotubes to read-across genotoxicity: A case study to evaluate the applicability of regulatory guidance. Computational Toxicology, 9, 22-35. 2019

BAuA 2013. German Federal Institute for Occupational Safety and Health. Announcement regarding hazardous substances. Manufactured nanomaterials. BekGS 527. BMBI 2013, 498-511 Nr. 25. 2013

BAua 2015. German Federal Institute for Occupational Safety and Health. Safe handling of nanomaterials and other advanced materials at workplaces. Brochure, see www.baua.de/nanoToGo. 2015

Boiteux, S., Gajewski, E., Laval, J. \& Dizdaroglu,M. Substrate specificity of the Escherichia coli FPG protein (formamidopyrimidine-DNA glycosylase): excision of purine lesions in DNA produced by ionizing radiation or photo. sensitization. Biochemistry 31,106-110. 1992 
Bos P, Gottardo S, Scott-Fordsmand JJ, van Tongeren M, Semenzin E, Fernandes T, Hristozov D, HundRinke K, Hunt N, Irfan MA, Landsiedel R, Peijnenburg W, Sánchez Jiménez A, van Kesteren P and Oomen A. 'The MARINA Risk Assessment Strategy: A Flexible Strategy for Efficient Information Collection and Risk Assessment of Nanomaterials', International Journal of Environmental Research and Public Health, 12: 14961. 2015

Bossa C, Benigni R, Tcheremenskaia O, Battistelli CL (Q)SAR Methods for Predicting Genotoxicity and Carcinogenicity: Scientific Rationale and Regulatory Frameworks. In: Nicolotti O. (eds) Computational Toxicology. Methods in Molecular Biology, vol 1800. Humana Press, New York, NY. 2018

Bouillard J, A. Vignes, A. Janès, D. Carson, A Krietsch, O. Holzschuh: Guidelines for Determining Protocols for the Explosivity and Flammability of Powders containing Nano-objects (for Transport, Handling and Storage ${ }^{\circ}$; 3rd European CEN Conference on Standardization for NanoTechnologies and NanoMaterials, 2 October 2018 at the Marriott Brussels Grand Place, Brussels, Belgium

Bove P, Malvindi MA, Kote SS, Bertorelli R, Summa M, Sabella S, Dissolution test for risk assessment of nanoparticles: a pilot study. Nanoscale, 9, 6315. 2017

BSI 'Nanotechnologies - Part 2: Guide to safe handling and disposal of manufactured nanomaterials'. http://www3.imperial.ac.uk/pls/portallive/docs/1/34683696.PDF. 2007

CEN/TS 17274:2018: Nanotechnologies - Guidelines for determining protocols for the explosivity and flammability of powders containing nano-objects (for transport, handling and storage). 2018

Collins AR, Annangi B, Rubio L, Marcos R, Dorn M, Merker C, Estrela-Lopis I, Cimpan MR, Ibrahim M, Cimpan E Ostermann M, Sauter A, Yamani NE, Shaposhnikov S, Chevillard S, Paget V, Grall R, Delic J, de-Cerio FG, Suarez-Merino B, Fessard V, Hogeveen KN, Fjellsbø LM, Pran ER, Brzicova T, Topinka J, Silva MJ, Leite PE, Ribeiro AR, Granjeiro JM, Grafström R, Prina-Mello A, Dusinska M.. High throughput toxicity screening and intracellular detection of nanomaterials. Wiley Interdiscip Rev Nanomed Nanobiotechnol. 9: e1413. 2017

Damoiseaux R, George S, Li M, Pokhrel S, Ji Z, France B, Xia T, Suarez E, Rallo R, Mädler L, Cohen Y, Hoek EMV, Nel A. No Time To Lose - High Throughput Screening To Assess Nanomaterial Safety. Nanoscale. 3: 1345-1360. 2011

Da Silva E, Kembouche $Y$, Tegner U, Baun A, Jensen KA. Interaction of biologically relevant proteins with $\mathrm{ZnO}$ nanomaterials: a confounding factor for in vitro toxicity endpoints. Toxicology In Vitro, 56, 41-51. 2019 
Da Silva E, Kembouche Y, Tegner U, Baun A, Jensen KA. Data article. Interaction of biologically relevant proteins with $\mathrm{ZnO}$ nanomaterials: a confounding factor for in vitro toxicity endpoints. Data in Brief. 2019

Dekkers S, Oomen AG, Bleeker EAJ, Vandebriel RJ, Micheletti C, Cabellos J, Janer G, Fuentes N, Vázquez-Campos S, Borges T, João Silva M, Prina-Mello A, a Movia D, Nesslany F, Ribeiro AR, Leite PE, Groenewold M, Cassee FR, Sips AJAM, Dijkzeul A, van Teunenbroek T and Wijnhoven SWP. 'Towards a nanospecific approach for risk assessment', Regulatory Toxicology and Pharmacology, 80: 46-59. 2016

Delaval M, Wohlleben W, Landsiedel R, Baeza-Squiban A, Boland S, Arch Toxicol 91: 163. 2017

Drasler B, Sayre P, Steinhäuser K G, Petri-Fink A, Rothen-Rutishauser B In vitro approaches to assess the hazard of nanomaterials Nanolmpact 8, 99- 116. 2017

Dusinska M., Collins A.R.: Detection of oxidised purines and UV-induced photoproducts in DNA, by inclusion of lesion-specific enzymes in the comet assay (single cell gell electrophoresis), Atlaalternatives to laboratory animals, 24, 405-411. 1996

Dusinska M, Boland S, Saunders M, Juillerat-Jeanneret L, Tran L, Pojana G, Marcomini A, Volkovova K, Tulinska J, Knudsen LE, Gombau L, Whelan M, Collins AR, Marano F, Housiadas C, Bilanicova D, Halamoda Kenzaoui B, Correia Carreira S, Magdolenova Z, Fjellsbø L, Huk A, Handy R, Walker L, Barancokova M, Bartonova A, Burello E, Castell J, Cowie H, Drlickova M, Guadagnini R, Harris H, Harju M, Heimstad ES, Hurbankova M, Kazimirova A, Kovacikova Z, Kuricova M, Liskova A, Milcamps A, Neubauerova E, Palosaari T, Papazafiri P, Pilou M, Poulsen MS, Ross B, Runden-Pran E, Sebekova K, Staruchova M, Vallotto D, Worth A. Towards an alternative testing strategy for nanomaterials used in nanomedicine: Lessons from NanoTEST. Nanotoxicology 7(S1), 118-132, 2015.

EC 1907/2006 Regulation (EC) No 1907/2006 of the European Parliament and of the Council of 18 December 2006 concerning the Registration, Evaluation, Authorisation and Restriction of Chemicals (REACH).

https://eur-lex.europa.eu/legal-content/EN/TXT/HTML/?uri=CELEX:02006R190720140410\&from $=\mathrm{DE}$

EC 1272/2008 Regulation (EC) No 1272/2008 of the European Parliament and of the Council of 16 December 2008 on classification, labelling and packaging of substances and mixtures (CLP). OJ No. L353, 31.12.2008, p. 1

EC 1223/2009 Regulation (EC) No $1223 / 2009$ of the European Parliament and of the Council of 30 November 2009 on cosmetic products.

https://eur-lex.europa.eu/legal-content/EN/TXT/PDF/?uri=CELEX:32009R1223\&from=EN 
ECHA 2008. "Guidance on information requirements and chemical safety assessment Chapter R.6: QSARs and grouping of chemicals." 2008.

ECHA 2017a . "Read-Across Assessment Framework (RAAF)" https://echa.europa.eu/documents/10162/13628/raaf en.pdf

ECHA 2017b. The use of alternatives to testing on animals for the REACH Regulation. Third report under Article 117(3) of the REACH Regulation. https://echa.europa.eu/documents/10162/13639/alternatives test animals 2017 en.pdf

ECHA 2017c. Guidance on information requirements and chemical safety assessment. Appendix R.6-1 for nanomaterials applicable to the guidance on QSARs and Grouping of Chemicals. https://echa.europa.eu/documents/10162/23036412/appendix r6 nanomaterials en.pdf

ECHA 2017d. Guidance for identification and naming of substances under REACH and CLP. https://echa.europa.eu/-/guidance-for-identification-and-naming-of-substances-underreach-and-clp

ECHA, JRC, RIVM. 2016. "Usage of (eco)toxicological data for bridging data gaps between and grouping of nanoforms of the same substance." 2016

Ellegaard-Jensen L, Jensen KA, Johansen A. Nano-silver induces dose-response effects on the nematode Caenorhabditis elegans. Ecotoxicology and Environmental Safety, 80, 216-223. 2012

EU 528/2012 Regulation (EU) No 528/2012 of the European Parliament and of the Council of 22 May 2012 concerning the making available on the market and use of biocidal products https://eur-lex.europa.eu/legal-content/EN/TXT/HTML/?uri=CELEX:32012R0528\&from=EN . 2012

EU 2018/1881 Commission Regulation (EU) 2018/1881 of 3 December 2018 amending Regulation (EC) No 1907/2006 of the European Parliament and of the Council on the Registration, Evaluation, Authorisation and Restriction of Chemicals (REACH) https://eur-lex.europa.eu/legal-content/EN/TXT/PDF/?uri=CELEX:32018R1881\&from=DE . 2018

EU 2011/696 Commission Recommendation on the definition of nanomaterial https://eur-lex.europa.eu/legal-content/EN/TXT/PDF/?uri=CELEX:32011H0696\&from=EN . 2011

EU US Roadmap Nanoinformatics 2030, Editors: Haase A und Klaessig Fred, DOI:10.5281/zenodo.1486012 https://www.nanosafetycluster.eu/Nanoinformatics2030.html. 2018 
Fleischer CC and Payne CK, Secondary Structure of Corona Proteins Determines the Cell Surface Receptors Used by Nanoparticles, J. Phys. Chem. B, 118, 14017-14026. 2014Fonseca AS, Kuijpers E, Kling KI, Nielsen SH, Levin M, Koivisto AJ, Fransman W, Yu YF, Antipov A, Jensen KA, Koponen IK. Particle release and control of worker exposure during laboratory-scale synthesis, handling and simulated spills of manufactured nanomaterials in fume-hoods. Journal of Nanoparticle Research, 20(2):48. 2018

Forster A, Olveira S, Seeger S, Nanotechnology in the market: Promises and realities. Internat J Nanotechnol 8: 592. 2011

Gajewicz A, Puzyn T, Rasulev B, Leszczynska D, Leszczynski J, Metal oxide nanoparticles: sizedependence of quantum-mechanical properties, Nanoscience \& Nanotechnology-Asia 1, 5358. 2011

Gebel T, Foth H, Damm G, Freyberge A, Kramer P-J, Lilienblum W, Röhl C, Schupp T, Weiss C, Wollin K-M, Hengstler JG, Manufactured nanomaterials: categorization and approaches to hazard assessment, Arch Toxicol, 88:2191-2211. 2014

Gerloff K, Landesmann B, Worth A, Munn S, Palosaari T, Whelan M. The Adverse Outcome Pathway approach in nanotoxicology. Computational Toxicology, 1: 3-11. 2017

Haase A and Lynch I. Quality in nanosafety - Towards reliable nanomaterial safety assessment. Nanolmpact 11:67-68. 2018

Halamoda-Kenzaoui B, Ceridono M, Urbán P, Bogni A, Ponti J, Gioria S, Kinsner-Ovaskainen A. The agglomeration state of nanoparticles can influence the mechanism of their cellular internalisation. J. Nanobiotechnol. 15, 48. 2017

Hansen SF, Larsen BH, Olsen SI and Baun A. 2007. 'Categorization framework to aid hazard identification of nanomaterials', Nanotoxicology, 1: 243-50.

Hansen SF and Baun A and Jensen KA. 'NanoRiskCat - A Conceptual Decision Support Tool for Nanomaterials'. Danish Environmental Protection Agency. Environmental Project No. 1372. 2011

Hansen SF, Jensen KA, Baun A. NanoRiskCategorization - NanoRiskCat - A Conceptual Tool for Categorization and Communication of Exposure Potentials and Hazards of Nanomaterials in Consumer Products. Journal of Nanoparticle Research, 16/1:2195. 2014

Hartmann NB, Jensen KA, Baun A, Rasmussen K, Rauscher H, Tantra R, Cupi D, Gilliland D, Pianella F, Riego Sintes JM. Techniques and protocols for dispersing nanoparticle powders in aqueous media - is there a rational for harmonization. Journal of Toxicology and Environmental Health, Part B: Critical Reviews 18(6), 299-326. 2015

Höck J, Behra R, Bergamin L, Bourqui-Pittet M, Bosshard C, Epprecht T, Furrer V, Frey S, Gautschi M, Hofmann H, Höhener K, Hungerbühler K, Knauer K, Krug H, Limbach L, Gehr P, Nowack B, 
Riediker M, Schirmer K, Schmid K, Som C, Stark W, Suarez Merino B, Ulrich A, von Götz N, Walser T, Wengert S, Wick P, Studer C. Guidelines on the Precautionary Matrix for Synthetic Nanomaterials. Federal Office of Public Health and Federal Office for the Environment. 2018

Hund-Rinke K, Herrchen M, Schlich K, Schwirn K, Völker D. Test strategy for assessing the risks of nanomaterials in the environment considering general regulatory procedures. Env Sci Eur. 27(1): 24.2015

Hund-Rinke K, Baun A, Cupi D, Fernandes TF, Handy R, Kinross JH, Navas JM, Peijnenburg W, Schlich K, Shaw BJ \& Scott-Fordsmand JJ. Regulatory ecotoxicity testing of nanomaterials - proposed modifications of OECD test guidelines based on laboratory experience with silver and titanium dioxide nanoparticles, Nanotoxicology, Vol 10(10), pp 1442-1447. 2016. DOI: 10.1080/17435390.2016.1229517

Hund-Rinke K, Schlich K, Kühnel D, Hellack B, Kaminski H, Nickel C. Grouping concept for metal and metal oxide nanomaterials with regard to their ecotoxicological effects on algae, daphnids and fish embryos. Nanolmpact 9, 52-60. 2018

Jeliazkova N, Chomenidis C, Doganis P, Fadeel B, Grafström R, Hardy B, Hastings J, Hegi M, Jeliazkov V, Kochev N, Kohonen P, Munteanu CR, Sarimveis H, Smeets B, Sopasakis P, Tsiliki G, Vorgrimmler D, Willighagen E. The eNanoMapper database for nanomaterial safety information. Beilstein J Nanotechnol. 6:1609-34. 2015

Jensen KA, Saber AT, Kristensen HV, Liguori B, Jensen AC $\varnothing$, Koponen IK \& Wallin H (2014). NanoSafer vs. 1.1 Nanomaterial risk assessment using first order modeling. Topical Scientific Workshop on Regulatory Challenges in Risk Assessment of Nanomaterials. Helsinki, 23-24 October, 2014

Judson R, Kavlock RJ, Martin MT, Reif T, Houck KA, Knudsen TB, Richard AM, Tice RR, Whelan M, Xia M, Huang R, Austin CP, Daston GP; Hartung T, Fowle III JR, Wooge W, Tong W, Dix DJ. Perspectives on Validation of High-Throughput Assays Supporting 21st Century Toxicity Testing. ALTEX, 30:51-66. 2013

Kar S; Gajewicz A; Puzyn T; Roy K; Leszczynski J. Periodic table-based descriptors to encode cytotoxicity profile of metal oxide nanoparticles: A mechanistic QSTR approach. Ecotoxicol. Environ. Saf. 107, 162-169. 2014

Karlsson HL, Gustafsson J, Cronholm P, Möller L. Size-dependent toxicity of metal oxide particles-a comparison between nano- and micrometer size. Toxicol. Lett. 188, 112-118. 2009

Kohonen P, Parkkinen JA, Willighagen EL, Ceder R, Wennerberg K, Kaski S, Grafström RC. A transcriptomics data-driven gene space accurately predicts liver cytopathology and druginduced liver injury. Nat Commun. 3;8:15932. 2017 
Koivisto AJ, Jensen AC $\varnothing$, Levin M, Kling KI, Dal Maso M, Nielsen SH, Jensen KA, Koponen IK. Testing a Near Field/Far Field model performance for prediction of particulate matter emissions in a paint factory. Environmental Science and Processes and Impacts. 17/1, 62-73. 2015

Koltermann-Jüllya J, Keller JG, Vennemann A, Werle K, Müller P, Ma-Hock L, Landsiedel R, Wiemann M, Wohlleben W. Abiotic dissolution rates of 24 (nano)forms of 6 substances compared tomacrophage-assisted dissolution and in vivo pulmonary clearance: Groupingby biodissolution and transformation. Nanoimpact 12, 29-41. 2018

Kuempel ED, Castranova V, Geraci CL, and Schulte PA. 'Development of risk-based nanomaterial groups for occupational exposure control', Journal of Nanoparticle Research, 14. 2012

Labib S, Williams A, Yauk CL, Nikota JK, Wallin H, Vogel U, Halappanavar S. Nano-risk Science: application of toxicogenomics in an adverse outcome pathway framework for risk assessment of multi-walled carbon nanotubes. Particle and Fibre Toxicology 13:15. 2016

Lamon L, Asturiol D, Richarz A, Joossens E, Graepel R, Aschberger K, Worth A. Grouping of nanomaterials to read-across hazard endpoints: From data collection to assessment of the grouping hypothesis by application of chemoinformatic techniques. Particle and Fibre Toxicology 15 (37). 2018

Landsiedel R 'Concern-driven integrated approaches for the grouping, testing and assessment of nanomaterials', Environmental Pollution, 218: 1376-80. 2016

Levin M, Koponen IK, Jensen KA. Release and exposure assessment of four pharmaceutical powders based on dustiness and evaluation of damaged HEPA filters. Journal of Occupational and Environmental Hygiene, 11/3, 165-177. 2014

Liguori B, Hansen SF, Baun A, and Jensen KA. Control banding tools for occupational exposure assessment of nanomaterials - Ready for use in a regulatory context? Nanolmpact, 2, 1-17. 2016

Lynch I, Weiss C and Valsami-Jones E 'A strategy for grouping of nanomaterials based on key physicochemical descriptors as a basis for safer-by-design NMs', Nano Today, 9: 266-70. 2014

Lynch I, Feitshans IL and Kendall M, Bio-nano interactions:new tools, insights and impacts: summary of the Royal Society discussion meeting Phil.Trans. R. Soc. B 370: 20140162. 2014

Marchese Robinson RL, Lynch I, Peijnenburg W, Rumble J, Klaessig F, Marquardt C, Rauscher H, Puzyn T, Purian R, Åberg C, Karcher S, Vriens H, Hoet P, Hoover MD, Hendren CO, Harper SL. How should the completeness and quality of curated nanomaterial data be evaluated? Nanoscale 8:9919-43. 2016

Mech A, Rasmussen K, Jantunen P, Aicher L, Alessandrelli M, Bernauer U, Bleeker EAJ, Bouillard J, Draisci R, Dusinska M, Encheva G, Di Prospero Fanghella P, Flament G, Haase A, Handzhiyski Y, Herzberg F, Huwyler J, Jacobsen NR, Jeliazkov V, Jeliazkova N, Nymark P, Grafström R, 
Oomen AG, Polci ML, Riebeling C, Shivachev B, Stateva S, Tanasescu S, Sandström J, Tsekovska R, Wallin H, Wilks MF, Zellmer S, Apostolova MD. Insights into possibilities for Grouping and Read-Across for Nanomaterials in EU Chemicals Legislation. Nanotoxicology: 123. 2018 DOI: 10.1080/17435390.2018.1513092.

Mikolajczyk A, Gajewicz A, Rasulev B, Schaeublin N, Maurer-Gardner E, Hussain S, Leszczynski J, Puzyn T. Zeta potential for metal oxide nanoparticles: a predictive model developed by a nano-quantitative Property-Relationship ApproachChem. Mater. 27, 7, 2400-2407. 2015

Mosquera J, García I, Liz-Marzán LM, Cellular Uptake of Nanoparticles versus Small Molecules: A Matter of Size, Acc. Chem. Res. 519, 2305-2313. 2018

Nel A, Xia T, Meng H, Wang X, Lin S, Ji Z and Zhang H. 'Nanomaterial toxicity testing in the 21st century: Use of a predictive toxicological approach and high-throughput screening', Accounts of Chemical Research, 46: 607-21. 2013

Nymark P, Kohonen P, Hongisto V, Grafström RL. Toxic and Genomic Influences of Inhaled Nanomaterials as a Basis for Predicting Adverse Outcome. Annals of the American Thoracic Society 5. 2018a

Nymark P, Rieswijk L, Ehrhart F, Jeliazkova N, Tsiliki G, Sarimveis H, Evelo CT, Hongisto V, Kohonen P, Willighagen E, Grafström RC. A Data Fusion Pipeline for Generating and Enriching Adverse Outcome Pathway Description. Toxicol Sci. 162:264-275. 2018b

OECD 2014. "Guidance on grouping of chemicals. second edition." In Series on Testing \& Assessment No. 194. 2014

OECD 2016a. "Categorization of manufactured nanomaterials." In Series on the Safety of Manufactured Nanomaterials No. 66, ENV/JM/MONO(2016)9. 2016

OECD 2016b. "Grouping and read-across for the hazard assessment of manufactured nanomaterials. Report from the expert meeting." In Series on the Safety of Manufactured Nanomaterials No. 76, ENV/JM/MONO(2016)59. 2016

Oomen AG, Bleeker EAJ, Bos PMJ, van Broekhuizen F, Gottardo S, Groenewold M, Hristozov D, HundRinke K, Irfan MA, Marcomini A, Peijnenburg WJGM, Rasmussen K, Sánchez Jiménez A, ScottFordsmand JJ, van Tongeren M, Wiench K, Wohlleben W and Landsiedel R. 'Grouping and read-across approaches for risk assessment of nanomaterials', International Journal of Environmental Research and Public Health, 12: 13415-34. 2015

Oomen AG, Steinhäuser KG, Bleeker EAJ, Van Broekhuizen F, Sips A, Dekkers S, Wijnhoven SWP and Sayre PG. Risk Assessment Frameworks for Nanomaterials: Scope, Link to Regulations, Applicability, and Outline for Future Directions in View of Needed Increase in Efficiency. Nanolmpact 9: 1-13. 2018 
Orts-Gil G, Natte K, Österle W. Multi-parametric reference nanomaterials for toxicology: state of the art, future challenges and potential candidates. RSC Adv. 3, 18202-18215. 2013

Pan Y, Neuss S, Leifert A, Fischler M, Wen F, Simon U, Schmid G, Brandau W, Jahnen-Dechent W. Size-dependent cytotoxicity of gold nanoparticles. Small 3, 1941-1949. 2007

Patlewicz G, Helman G, Pradeep P, Shah I. Navigating through the minefield of read-across tools: A review of in silico tools for grouping. Comput Toxicol. 3:1-18. 2017

Puzyn T, Rasulev B, Gajewicz A, Hu X, Dasari TP, Michalkova A, Hwang HM, Toropov A, Leszczynska D, Leszczynski J. Using nano-QSAR to predict the cytotoxicity of metal oxide nanoparticles. Nat. Nanotechnol. 6, 175-178. 2011

Rasmussen K, Rauscher H, Kearns P, González M, Riego Sintes J. Developing OECD Test Guidelines for Regulatory Testing of Nanomaterials to ensure mutual acceptance of test data. Regulatory Toxicology and Pharmacology. 104, 74-83. 2019

RCC, Regulatory Cooperation Council. "Work element 2, Priority setting: Development of a Joint Nanomaterials Classification Scheme". 2013

RCC, Regulatory Cooperation Council. "Work element 3, Risk Assessment/Risk Management". 2014

Reif, DM, Martin MT, Tan SW, Houck KA, Judson RS, Richard AM, Knudsen TB, Dix DJ, and Kavlock RJ. 'Endocrine Profiling and Prioritization of Environmental Chemicals Using ToxCast Data', Environmental Health Perspectives, 118: 1714-20. 2010

Reif, DM, M. Sypa, E. F. Lock, F. A. Wright, A. Wilson, T. Cathey, R. R. Judson, and I. Rusyn. 'ToxPi GUI: An interactive visualization tool for transparent integration of data from diverse sources of evidence', Bioinformatics, 29: 402-03. 2013

Ribeiro AR, Leite PE, Falagan-Lotsch P, Benetti F, Micheletti C, Budtz HC, Jacobsen NR, Lisboa-Filho PN, Rocha LA, Kühnel D, Hristozov D, Granjeiro JM. Challenges on the toxicological predictions of engineered nanoparticles Nanolmpact. 8, 59- 72. 2017

Riediker M, Ostiguy C, Triolet J, Troisfontaine P, Vernez D, Bourdel G, Thieriet N, Cadene A. Development of a Control Banding Tool for Nanomaterials, Journal of Nanomaterials, Volume 2012, Article ID 879671, 8 pages, doi:10.1155/2012/87967, Hindawi Publishing. 2012

Sellers K, Deleebeeck NME, Messiaen M, Jackson M, Bleeker EAJ, Sijm DTHM, and van Broekhuizen FA. 'Grouping nanomaterials. A strategy towards grouping and read-across'. 2015

Shang L, Nienhaus K, Nienhaus GU. Engineered nanoparticles interacting with cells: size matters J Nanobiotechnology. 12: 5. 2014

Siegrist S, Cörek E, Detampel P, Sandström J, Wick P, Huwyler J. Preclinical hazard evaluation strategy for nanomedicines. Nanotoxicology 2018, doi:10.1080/17435390.2018.1505000

Sizochenko N, Rasulev B, Gajewicz A, Kuz'min V, Puzyn T, Leszczynski J. From basic physics to mechanisms of toxicity: the "liquid drop" approach applied to develop predictive 
classification models for toxicity of metal oxide nanoparticles. Nanoscale, 6, 13986-13993. 2014

Sizochenko N, Jagiello K, Leszczynski J, Puzyn T. How the "Liquid Drop" Approach Could Be Efficiently Applied for Quantitative Structure-Property Relationship Modeling of Nanofluids. The Journal of Physical Chemistry C 119(45): 25542-25547. 2015

SMP 2013. Swiss Precautionary Matrix "Guidelines on the Precautionary Matrix for Synthetic Nanomaterials." (Swiss) Federal Office of Public Health FOPH and Federal Office for the Environment (FOEN). 2013

Stone V, Pozzi-Mucelli S, Tran L, Aschberger K, Sabella S, Vogel U, Poland C, Balharry D, Fernandes T, Gottardo S, Hankin S, Hartl MGJ, Hartmann N, Hristozov D, Hund-Rinke K, Johnston H, Marcomini A, Panzer O, Roncato D,Saber AT, Wallin H, and Scott-Fordsmand JJ. 'ITS-NANO Prioritising nanosafety research to develop a stakeholder driven intelligent testing strategy', Particle and Fibre Toxicology, 11. 2014

Tănăsescu S, Precupaş A, Gheorghe D, Teodorescu F, Botea-Petcu A, Sandu R, Popa VT, Mariussen E, Yamani NEl, Giusti A, Haase A, Rundén-Pran E and Dusinska M, Correlation between the thermodynamic parameters of the nanoparticles/proteins interactions and the dominant contributions determining the toxicity of the nanomaterials, $9^{\text {th }}$ International Conference on Nanotoxicology (NanoTox), 18-21 September 2018, Düsseldorf/Neuss, Germany

Utembe W, Potgieter K, Stefaniak AB, Gulumian M. Dissolution and biodurability: Important parameters needed for risk assessment of nanomaterials. Part Fibre Toxicol. 12:11. 2015

Vietti G, Lison D, van den Brule S. Mechanisms of lung fibrosis induced by carbon nanotubes: towards an Adverse Outcome Pathway (AOP). Particle and Fibre Toxicology 13:11. 2016

Walczyk D, Bombelli FB, Monopoli MP, Lynch I, Dawson KA. What the cell 'sees' in bionanoscience. J. Am. Chem. Soc. 132,5761-5768. 2010

Worth A, Aschberger K, Asturiol Bofill D, Bessems J, Gerloff K, Graepel R, Joossens E, Lamon L, Palosaari T and Richarz A, Evaluation of the availability and applicability of computational approaches in the safety assessment of nanomaterials, EUR 28617 EN, Publications Office of the European Union, Luxembourg, ISBN 978-92-79-68708-2, doi:10.2760/248139, JRC106386. 2017

Zhu ZJ, Posati T, Moyano DF, Tang R. Yan B, Vachet RW, Rotello VM, The interplay of monolayer structure and serum protein interactions on the cellular uptake of gold nanoparticles, Small 8, No. 17, 2659-2663. 2012 


\section{Highlights}

1) Overview of existing large, comprehensive nanomaterial grouping frameworks and other useful nanomaterial grouping approaches

2) Comparison of underlying grouping principles, advantages and disadvantages of each approach including an assessment of (regulatory) applicability

3) Improvements achieved within the European H2020 Project NanoReg2

4) Challenges faced when aiming at putting grouping into practice based on case studies conducted in NanoReg2 including recommendations to overcome them

5) Outlook with respect to open research needs for putting grouping into practice 